\title{
Powder bed fusion additive layer manufacturing of titanium alloys
}

\author{
Hossein Eskandari Sabzi*1 \\ ${ }^{1}$ Department of Engineering, Lancaster University, Gillow Ave, Bailrigg, Lancaster, LA1 4YW, United \\ Kingdom
}

\begin{abstract}
Powder bed fusion techniques for additive layer manufacturing are reviewed with a focus on titanium alloys production. Selective laser melting and electron beam melting are discussed in terms of feedstock production and processing-microstructure relationships. To control the powder bed fusion processes, an outline is presented on the computational modelling approaches for simulating process parameters and defects such as residual stresses and porosity at different length scales. It is concluded that by improving powder production techniques, designing new alloys and further developing additive layer manufacturing hardware, powder bed fusion techniques can reach commercial maturity.
\end{abstract}

Keywords - Additive layer manufacturing, Powder bed fusion, Titanium alloys, Computational methods

\section{Introduction}

Additive Layer Manufacturing (ALM) is a layer-by-layer method to make three-dimensional (3D) objects directly from computer aided design (CAD) files. It was first adopted as a method for

*Corresponding author e-mail address: h.eskandarisabzi@lancaster.ac.uk 
rapid prototyping, but today its commercial application is increasing in different industries such as aerospace, automotive and medical devices [1]. ALM processes can be divided into four main categories: powder bed fusion (PBF), directed energy deposition (DED), binder jetting and sheet lamination.

ALM becomes attractive where the conventional manufacturing methods are limited and production times and costs are high. This includes products of complex geometry, and those where material waste is undesired [2]. Titanium alloy components are amongst those requiring costly production methods. This has motivated the development of alternative methods such as ALM [3, 4, 5, 6]. ALM is a design-driven process allowing for shapes of a high degree of complexity. Metallic powder processing is of great importance to metallurgical applications including ALM; metallic powders are used as feedstock for PBF, DED and binder jetting. Among these techniques, PBF and DED directly melt powder materials with high energy sources (either laser or an electron beam) aiming to achieve fully dense parts. Particularly for metals such as titanium alloys, PBF techniques including selective laser melting (SLM) and electron beam melting (EBM) are preferred due to the direct near net-shape high quality fabrication [7]. A schematic of the PBF processes is shown in Fig. 1.

SLM typically uses a 200-400 W laser under an inert gas environment, such as argon or nitrogen, while EBM utilises a focused electron beam of about $60 \mathrm{~kW}$ under vacuum [8, 5]. The precision and final surface quality of the SLM as-built parts are better than EBM, but at the expense of longer build times and higher residual stresses [9, 10].

The aim of this work is to provide a comprehensive review of the production of titanium alloys by PBF, covering steps from the production of high-quality feedstock to post-processing. Processingmicrostructure relationships have been reviewed, including computational methods to describe them. This review is concluded with suggestions for improving the rate and reliability of PBF processes. 


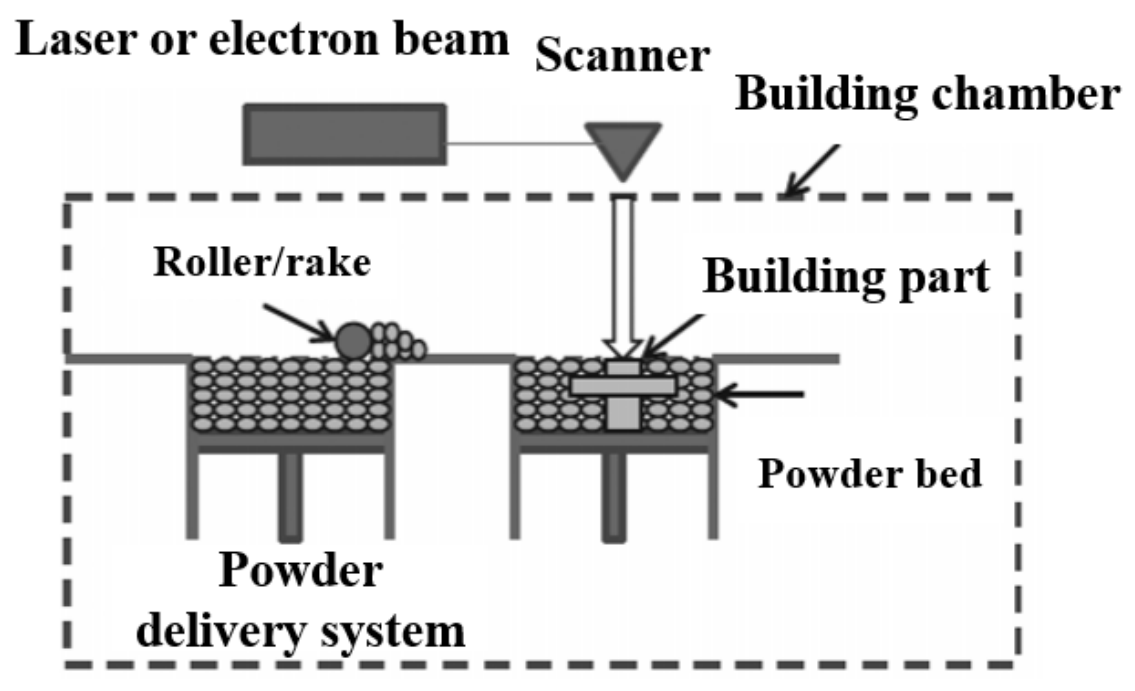

Figure 1: Schematic of PBF ALM processes [3].

\section{Titanium metallurgy}

PBF methods have been adopted for the production of titanium alloys for aerospace and automotive industry as well as for biomedical applications [11, 12, 13, 14, 15, 16]. Amongst titanium alloys, Ti-6Al-4V has received most of the attention, this is due to its high strength-to-weight ratio. Its equilibrium microstructure contains $\alpha$ and $\beta$ phases which respectively have a hexagonal close packed (HCP) and body centered cubic (BCC) lattice structures. The $\alpha$ phase is stable at room temperature, often associated with strength, but $\beta$ phase is metastable and is often responsible for ductility. Under rapid cooling conditions, a brittle HCP martensitic phase $\left(\alpha^{\prime}\right)$ can be formed, which presence can be detrimental to mechanical properties [2, 6]. A list of typical titanium alloys that have been processed by ALM, and their typical associated microstructures is shown in Table 1.

The microstructures of PBF-fabricated parts are unique due to the complex thermal cycles that a part experiences during the layer-by-layer melting and solidification. As a result, the material may experience repeated solid-solid and liquid-solid phase transformations. An example of the thermal profile for a layer of PBF-processed Ti-6Al-4V is shown in Fig. 2a. In this case, the alloy has experienced two liquid-solid and two $\beta \rightarrow \alpha$ transformations. Therefore, many of the PBF 
Table 1: Typical titanium alloys produced by ALM

\begin{tabular}{lcc} 
Alloy & Microstructure & Reference \\
\hline \hline Ti-6Al-4V & $\alpha+\beta+\left(\alpha^{\prime}\right)$ & {$[6]$} \\
Ti-24Nb-4Zr-8Sn (Ti2448) & $\beta$ & {$[17]$} \\
Ti-6Al-7Nb & $\beta$ & {$[18]$} \\
Ti-13Nb-13Zr & $\beta$ & {$[18]$} \\
Ti-13Zr-Nb & $\beta$ & {$[18]$} \\
Ti-6Al-2V-1.5Mo-0.5Zr-0.3Si & $\alpha+\beta$ & {$[19]$} \\
Ti-La & $\alpha+\beta$ & {$[20]$} \\
\hline
\end{tabular}

processes result in metastable microstructures which may vary in each layer of the as-built part [21].

$\mathrm{PBF}$ is a process requiring rapid solidification. Reports show that cooling rates between $10^{3}$ to $10^{8} \mathrm{~K} / \mathrm{s}$ are achieved for SLM and between $10^{3}$ and $10^{4} \mathrm{~K} / \mathrm{s}$ for EBM [21]. Hence, a fine-grained microstructure has usually been observed in PBF parts. Moreover, the heat flow in PBF processes is directional and can lead to the formation of columnar grains with high texture which can increase anisotropy [22]. Typical electron backscatered diffraction (EBSD) micrographs of microstructures obtained from Ti-6Al-4V SLM and EBM are presented in Fig. 2b and c. The microstructure of the SLM part is finer and contains more $\alpha^{\prime}$ than the EBM specimen, this is due to its higher cooling rates.

Producing a structurally sound, defect-free and reliable part via PBF requires the understanding of two main challenges. The production of a high-quality powder feedstock demanding control of powder production methods, and the microstructural evolution during PBF processing.

\section{Strategies for titanium powder production}

The quality and consistency of the PBF components depend on the characteristics of the starting powder. The most critical issues in titanium powders are particle size distribution (PSD), particle shape, flowability and chemical composition. For SLM, PSD should be between 10 to $45 \mu \mathrm{m}$, while powders can be in the range of 45 to $106 \mu \mathrm{m}$ for EBM [25]. In order to improve flowability, the particles should be spherical [26]. Flowability is an important factor because if the powder cannot 

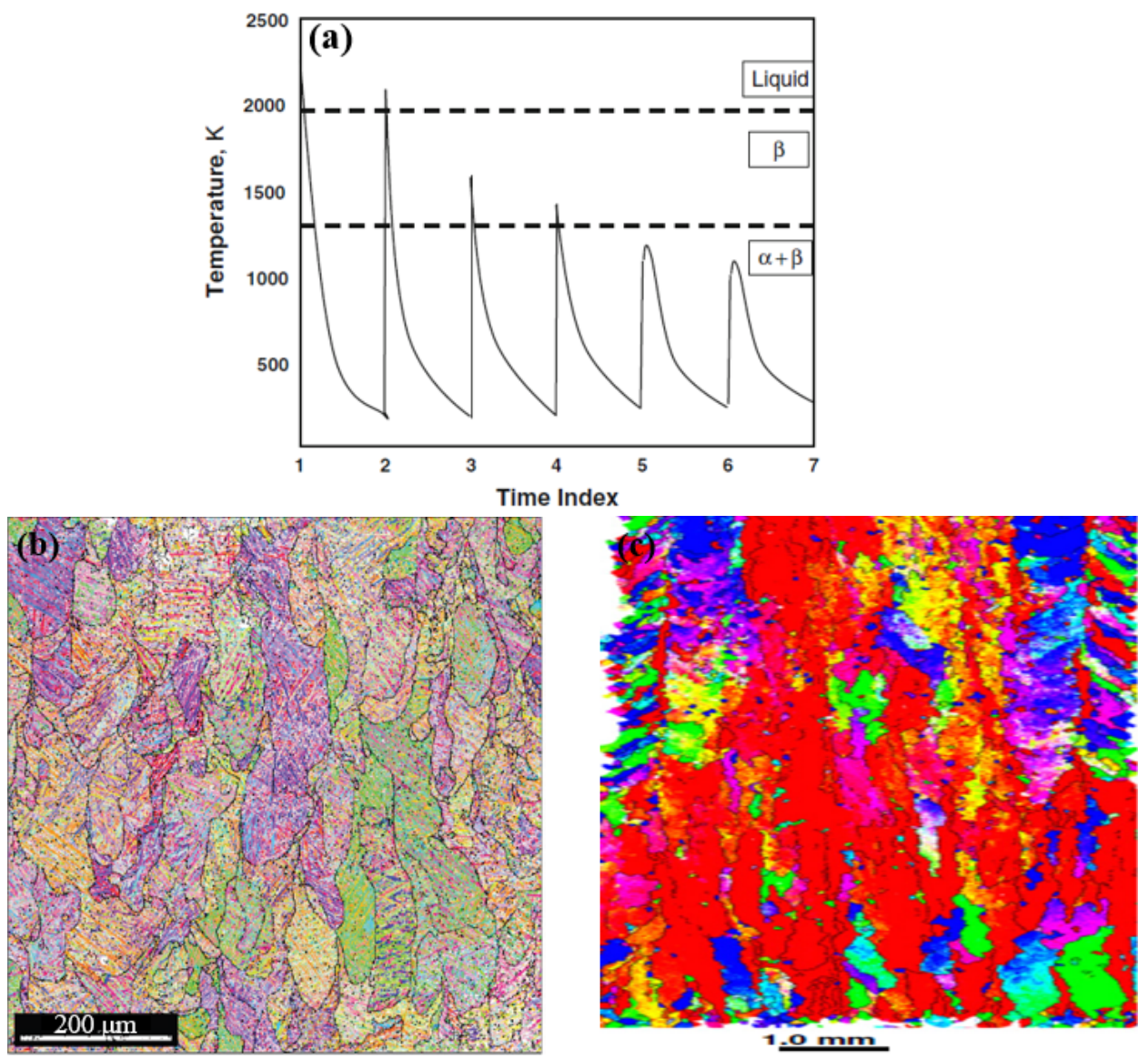

Figure 2: (a) Thermal profile of a layer of Ti-6Al-4V during ALM [21], (b) inverse pole figures (IPF) of an SLM produced [23] and (c) an EBM produced Ti-6Al-4V [24]. 
be distributed evenly in the powder bed, it leads to porosity in the as-built part. The chemical composition of the powder must be within specification. This is particularly important for recycled powders. For example, Tang et al. [27] showed that powder recycling after EBM process of Ti-6Al$4 \mathrm{~V}$ can increase the oxygen content and decrease the aluminium and vanadium concentration. Such concentration changes can be intensified by increasing the reusing cycles. However, flowability can be improved by reusing the powder. Reports [27] indicate that by mixing with virgin powder, the composition specifications can be met and the subsequent mechanical properties may not be badly influenced.

The quality of the powder feedstock depends on its production process. This can be via water, gas or plasma atomisation, hydryde-dehydryde (HDH) processing, the titanium research organisation (TiRO) process, and by granulation-sintering-deoxygenation (GSD). A list of methods for metallic powder production is shown in Fig. 3; those used to produce spherical titanium powder are highlighted in red. Schematics of each powder production method are shown in Fig. 4.

Most of the spherical titanium alloy powder used for ALM applications is produced via atomisation, the technique of breaking up molten liquid into particles. The most simple and low-cost atomisation technique is water atomisation. It uses water jets to atomise the molten metal (Fig. 4a). The powder produced by this method may have irregularities in shape suffering from poor density, flowability and high amounts of oxygen. Therefore, water atomisation is not preferred for ALM, especially for titanium alloys [28].

The gas atomisation (GA) process uses inert gasses such as argon as atomising medium, in order to minimise the risk of oxidation and contamination, especially in the case of reactive metals such as titanium. For titanium, interstitial elements such as oxygen and nitrogen must be controlled. Therefore, vacuum induction melting furnaces are adopted in the vacuum induction gas atomisation (VIGA) process. The furnace can usually be installed directly above the atomisation chamber, and the melt stream enters the chamber without a tundish. Then the molten metal is atomised by a high-pressure gas (Fig. 4b).

Even if the interstitial elements can be controlled at VIGA, there is risk of contamination by ex- 


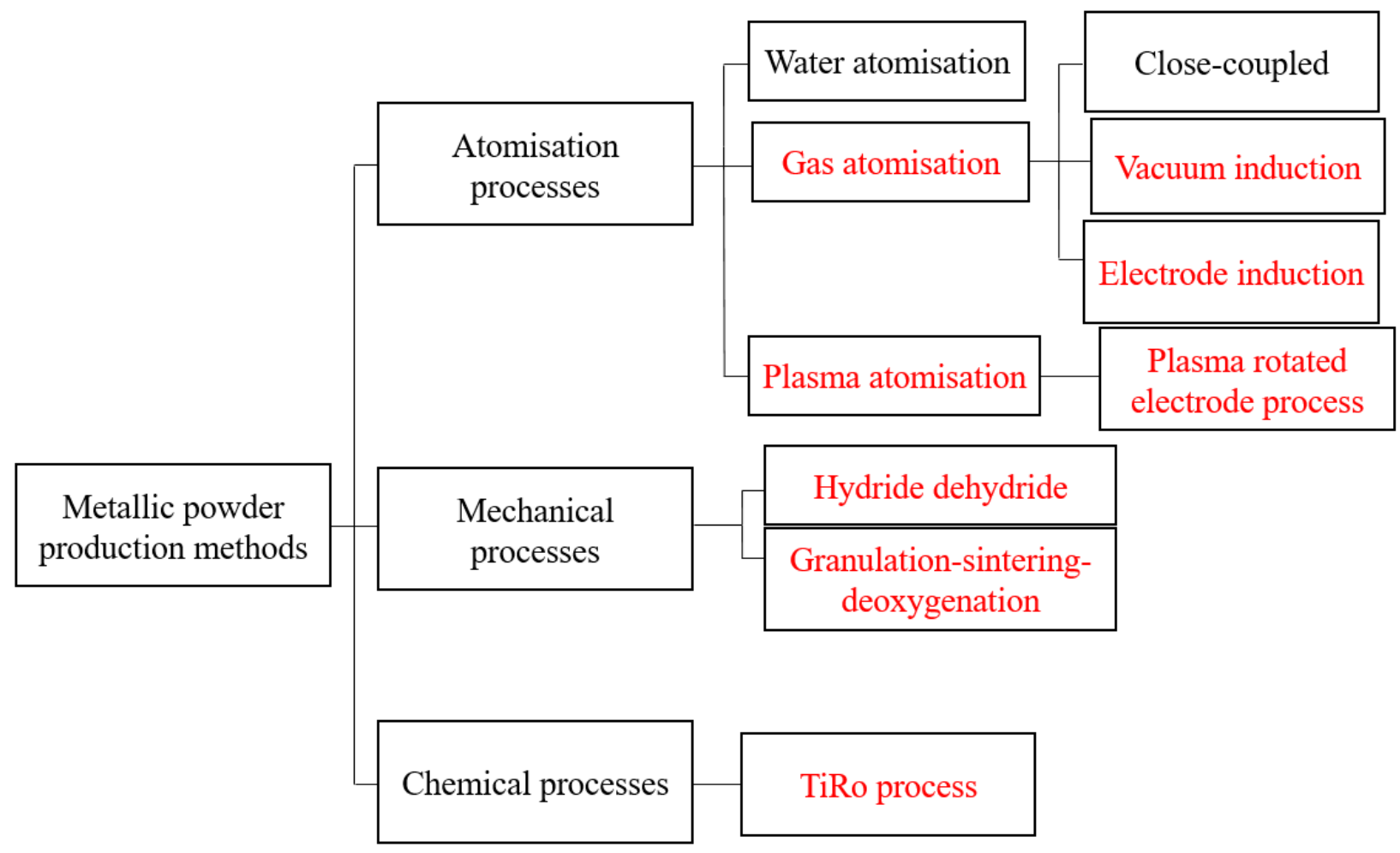

Figure 3: Metallic powder production methods. The methods for spherical Ti powder production have been shown in red. 

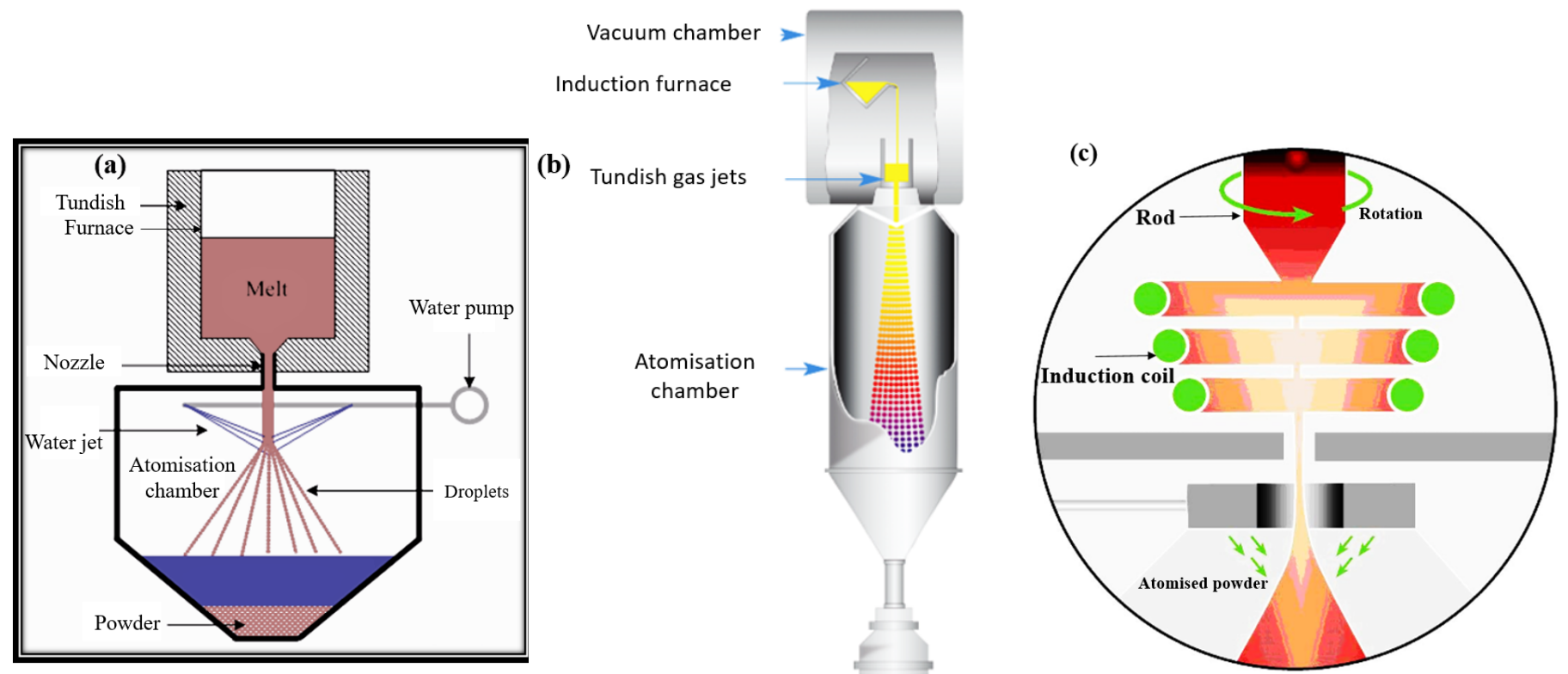

(d)
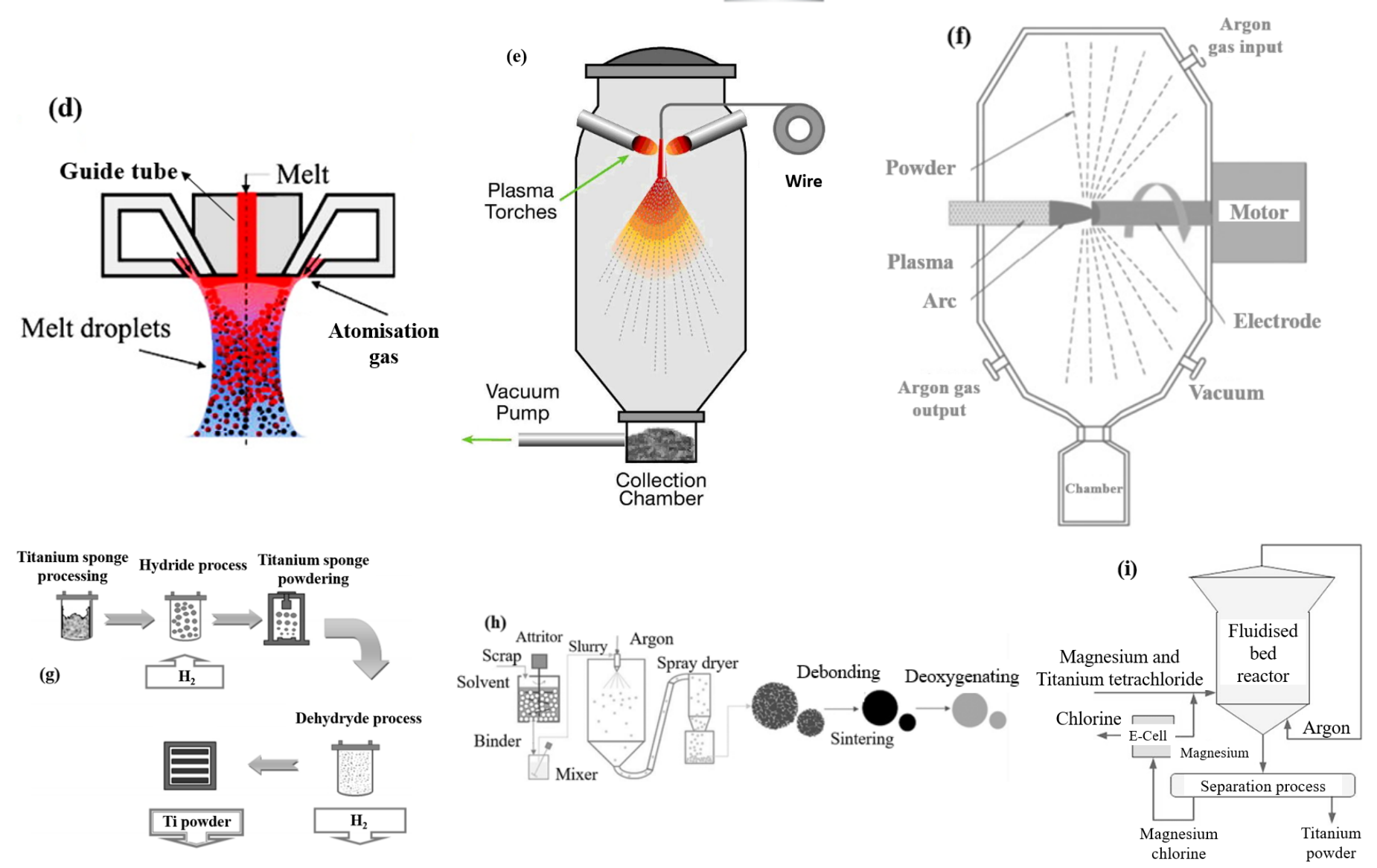

Figure 4: Schematics of different powder production methods: (a) water atomisation, (b) vacuum induction gas atomisation (VIGA), (c) electrode induction gas atomisation (EIGA), (d) close coupled gas atomisation (CCGA), (e) plasma atomisation (PA), (f) plasma rotated electrode process (PREP), (g) hydryde-dehydryde (HDH), (h) granulation-sintering-deoxygenation (GSD), (i) titanium research organisation (TiRO) process. 8 
posure to refractory materials from ceramic crucibles. A solution to contamination is the electrode induction gas atomisation (EIGA) process. In this, the feedstock is in the form of a rod and it is melted by an induction coil further entering the atomisation chamber (Fig. 4c). EIGA is a noncontact melting method and can be operated under high vacuum conditions; it has been widely used for producing Ti-6Al-4V, as it minimises the risk of contamination [29].

The close-coupled gas atomisation (CCGA) is a less popular method for producing reactive metals, such as titanium, where the melt is broken up by the direct collision of high-pressure gas under the tip of an extended melt guide tube (Fig. 4d) [25].

Plasma Atomisation (PA) uses wire as feedstock and the melting source is plasma. In this process (Fig. 4e), the wire is fed into the atomisation chamber and it is melted and atomised simultaneously by plasma torches and gas, respectively [28]. Replacing the feedstock by a rotating bar leads to the plasma rotating electrode process (PREP) (Fig. 4f). As the rotating bar enters the atomisation chamber, the end of the bar is melted by plasma. The material is ejected from its surface. The melt solidifies before hitting the walls of the chamber [30]. It should be noted that PREP process is also performed under vacuum.

Mechanical powder production processes involve crushing, milling and fracturing to resize larger lumps of metal feedstock into finer powder particles. There are two main mechanical processes that can be used to produce metallic powders. The hydride-dehydride (HDH) and granulationsintering-deoxygenation (GSD) methods. HDH exploits the brittleness of certain metals like titanium hydrides, which are formed by hydrogen and heat. The lumps that are formed are brittle and can be fractured into the required particle size distribution by crushing them. At the end, the redundant hydrogen is removed using vacuum and heat to produce metal powder particles (Fig. 4g) [31]. In order to improve the quality of the powders produced by $\mathrm{HDH}$, plasma spheroidisation should be done to improve the sphericity of the powders produced. GSD is a newly developed process that has been developed to produce Ti-6Al-4V without using high-cost melting and atomisation techniques. In this process, three low-cost processes of granulation, sintering and deoxygenation are mixed to produce spherical titanium alloys. The feedstock in this method can be titanium scrap 
Table 2: Summary of different methods of spherical Ti powder production.

\begin{tabular}{lccc} 
Methods & Feedstock & Benefit & Drawback \\
\hline \hline VIGA & Bar & High sphericity, high cleanliness & Satellites, porosity \\
EIGA & Bar & Fine powder & Porosity, high argon flow rate \\
PA & Wire & Less satellites, fine powder & Expensive feedstock, porosity \\
PREP & Bar & High purity, no satellites & Coarse powder \\
HDH & Ingot & Low Cost & Irregular particle morphology \\
GSD & Scrap & Low cost, low waste & Particle bonding during sintering \\
\hline
\end{tabular}

and the particle distribution size and low amounts of oxygen can be controlled. A full schematic of this method is shown in Fig. 4h [32].

Titanium powder may be produced via chemical reactions as well, such as in TiRO, a two stage process where titanium tetrachloride is thermally reduced to a magnesium chloride/titanium composite in the presence of $\mathrm{Mg}$ in a reactor. Then the composite is separated by using vacuum distillation (Fig. 4i). [33].

Fig. 5 shows typical scanning electron microscope (SEM) micrographs of the alloy powders produced by GA, PREP and PA, which are the most common methods for producing titanium alloys ALM feedstock. The PREP and PA powders are spherical. GA powders are spherical too, but the presence of satellites increase the part surface roughness. Satellites are due to the circulation of gas in the atomising chamber leading to the collision of fine particles and partially melted particles [34]. Compared with the two other methods, PREP-produced powders have the most homogeneous distribution and flowability. As GA powders have satellites, they can lead to porosity in the fabricated part. Using gas atomisation and plasma atomisation processes, fine spherical powder with a controlled PSD can be produced $(10-300 \mu \mathrm{m})$. However, the PSD of the powders produced by PREP is coarser and between 50-350 $\mu \mathrm{m}$ [35]. Therefore, most of the PREP powders cannot be used as SLM feedstock. As a summary, the advantages and drawbacks of each common titanium powder production methods are shown in Table 2. 

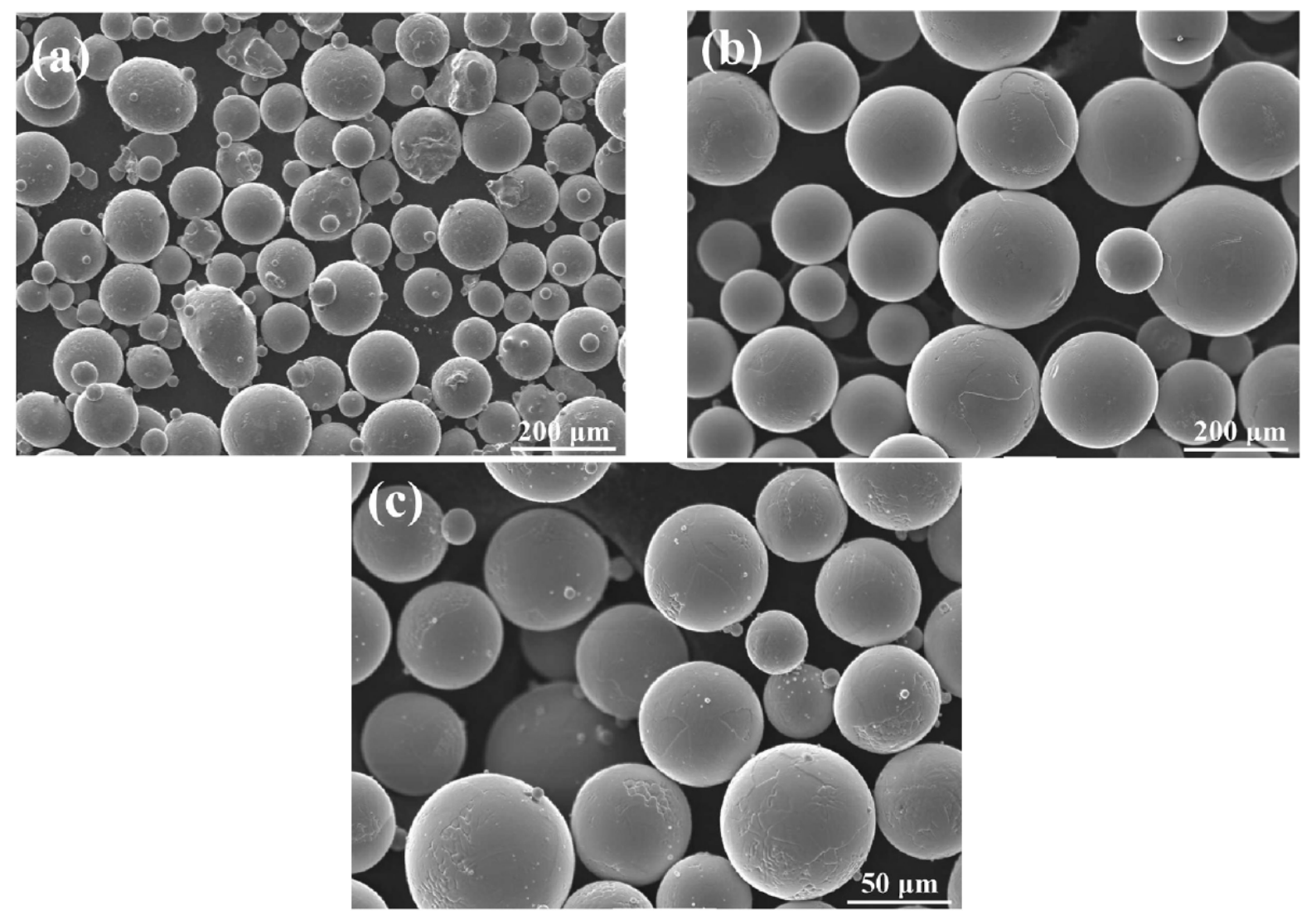

Figure 5: Morphology of the Ti-6Al-4V alloy powder produced by (a) GA, (b) PREP and (c) PA [36]. 

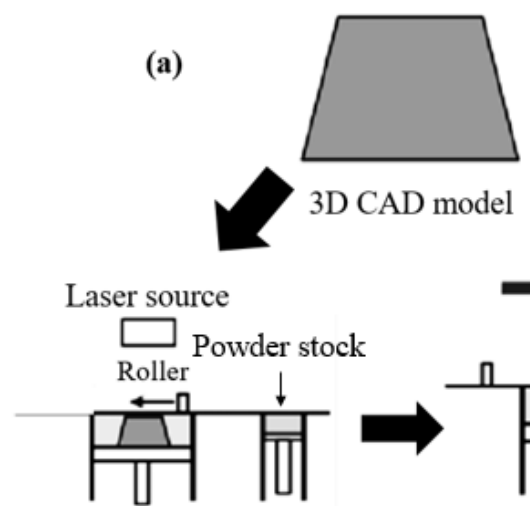

Powder feeding

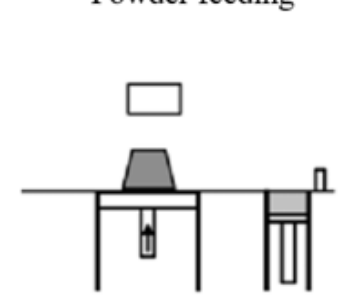

Fabricated part removal

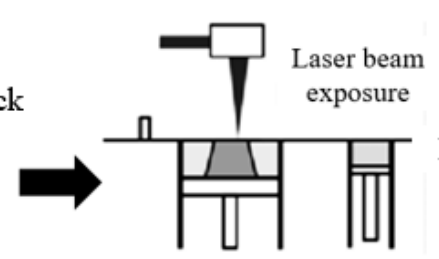

Selective melting

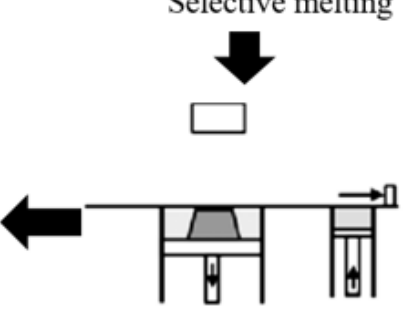

Lowering of building part

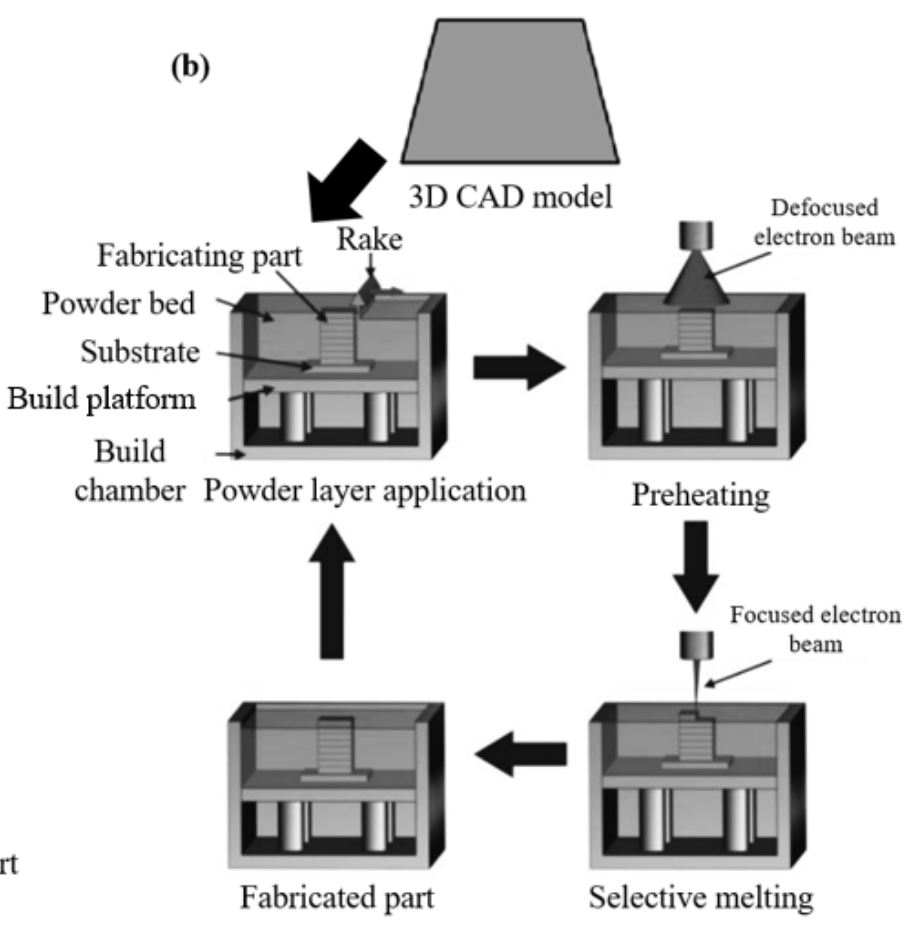

Figure 6: The schematics of the iterative steps of (a) SLM [38] and (b) EBM process [39].

\section{Processing-microstruture relationships}

As is shown schematically in Fig. 6, the sequence of PBF processes is as follows. Firstly, the 3D CAD model of the part is divided into layers. A roller (in SLM) or a rake (in EBM) spread a thin layer of powder over the build platform. The energy source, which is either laser or electron beam, scan the powder bed with a predetermined path (strategy). Depending on the heat source and power level of the system, the powder bed layer is melted into the desired shape. In EBM, the substrate is preheated to a maximum of about $0.8 T_{m}$ (melting temperature). The preheating temperature depends on the powder characteristics and can be higher than $700^{\circ} \mathrm{C}$ for titanium alloys. Once the layer is complete, the platform lowers to the desired layer thickness and the next layer of powder is spread over the working area and melting is repeated [37, 10]. At this moment, SLM dominates PBF commercial systems.

In these processes, the processing parameters are set to deliver enough energy to fuse all of the particles in the melt pool above the liquidus temperature. As the heat source moves on, heat is 
conducted away from molten metal and it solidifies quickly. In general, the mechanical properties of the titanium alloys produced by PBF methods are acceptable. There are numerous reviews on mechanical properties of ALM-built titanium components [6, 40]. The characteristics of the built part depend on processing parameters such as energy source power, focused spot size, layer thickness, scan speed, and scan strategy. However, reaching a full density part without post-processing requires high input energy levels to fully melt the feedstock and this itself may lead to undesirable results such as distortion and residual stresses.

Due to the high affinity of titanium to react with oxygen and in order to avoid the formation of oxides, PBF processes generally occur under vacuum (EBM) or an inert atmosphere of nitrogen, argon or helium (SLM).

After the processing is finished, the as-built material is separated from the build platform. Due to the layer-by-layer nature of the process, surface roughness is among the issues of PBF methods. Minimising the layer thickness, which requires higher scan speed, can decrease the roughness of the as-built part. However, this may lead to the formation of undesirable porosity or longer build times, increasing component cost. Therefore, some finishing steps such as milling, grinding and polishing may be needed to improve the quality of the surface of as-built parts [41]. As discussed in section 2, the microstructure of the as-built parts are complex, and in the case of SLM, the produced parts may contain large amounts of residual stresses. Therefore, post-processing heat treatments are usually applied. ASTM 2924 specification for ALM of Ti-6Al-4V with PBF methods was approved in recent years [21]. This standard contains a section for post-processing of ALM produced Ti-6Al-4V via various heat treatments such as stress releiving (at $650-700^{\circ} \mathrm{C}$ ), annealing, solution treatment (at $1010^{\circ} \mathrm{C}$ ), ageing and hot isostatic pressing (HIP). Such post-processing steps lead to microstructures with lower residual stresses, as well as martensite decomposing into $\alpha+\beta$ structures with coarser grains [37]. HIP can relieve the stresses and decrease the amount of porosity in as-built parts. Typically, the HIP temperature for titanium alloys is about $900^{\circ} \mathrm{C}$. The pressure is $\sim 100 \mathrm{MPa}$ and the time is between 2 and 4 hours [42]. 


\subsection{Microstructural inhomogenieties}

Inhomogenieties that have been reported in literature for PBF of titanium alloys include variations in grain size and highly texturised microstructures. Both are related to process parameters (heat input and scan strategy). The processing conditions are often summarised using the volumetric heat input, $E_{v}$, where $E_{v}=P /(v \cdot h \cdot d)$, where $P$ is the beam power, $v$ is the scan speed, $h$ is the hatch spacing (the center to center distance between melt pools in the build plane) and $t$ is the layer thickness.

The microstructure of SLM fabricated Ti-6Al-4V is strongly dependent on the volumetric heat input of the laser. At low scan speeds (high volume energy) a phase transformation of $\beta \rightarrow \alpha$ occurs during cooling and leads to coarse grains. At higher scan speeds and low volume energies, $\beta$ phase transforms into $\alpha^{\prime}$ martensite. At the highest scan speeds, higher grain refinement can be achieved [37]. With increasing the heat input, coarser grains can be achieved. Recently, GalindoFernandez et al. [2] developed a physics-based model to relate grain size and morphology of ALM produced Ti-6Al-4V to the mechanical properties to predict the effects of processing conditions on deformation behaviour.

Two common grain morphologies that have been seen in ALM-fabricated parts are columnar and equiaxed. The columnar grains are generally coarse and anisotropic, while the equiaxed grains are fine and isotropic [6]. The fraction of columnar and equiaxed grains can be tailored via thermal gradient $(\mathrm{G})$ and solidification rate $(\mathrm{R})$ control. As shown in Fig. 7, by decreasing the thermal gradient and increasing the solidification rate, the portion of equiaxed grains can be increased. It can be seen that, generally, as the melt pool begins to solidify, columnar grains form and move towards a mixture of equiaxed and columnar during solidification and finally a fully equiaxed microstructure is expected at the end of ALM processing [43]. Recently, Kumar et al. [44] succeeded to almost completely replace the columnar grains by equiaxed grains by choosing an appropriate combination of layer thickness and scan rotation in an SLM produced Ti-6Al-4V alloy.

As is discussed in section 2, the microstructures of the PBF-produced titanium alloys are highly texturised. This is because of directional solidification and epitaxial grain growth of titanium 


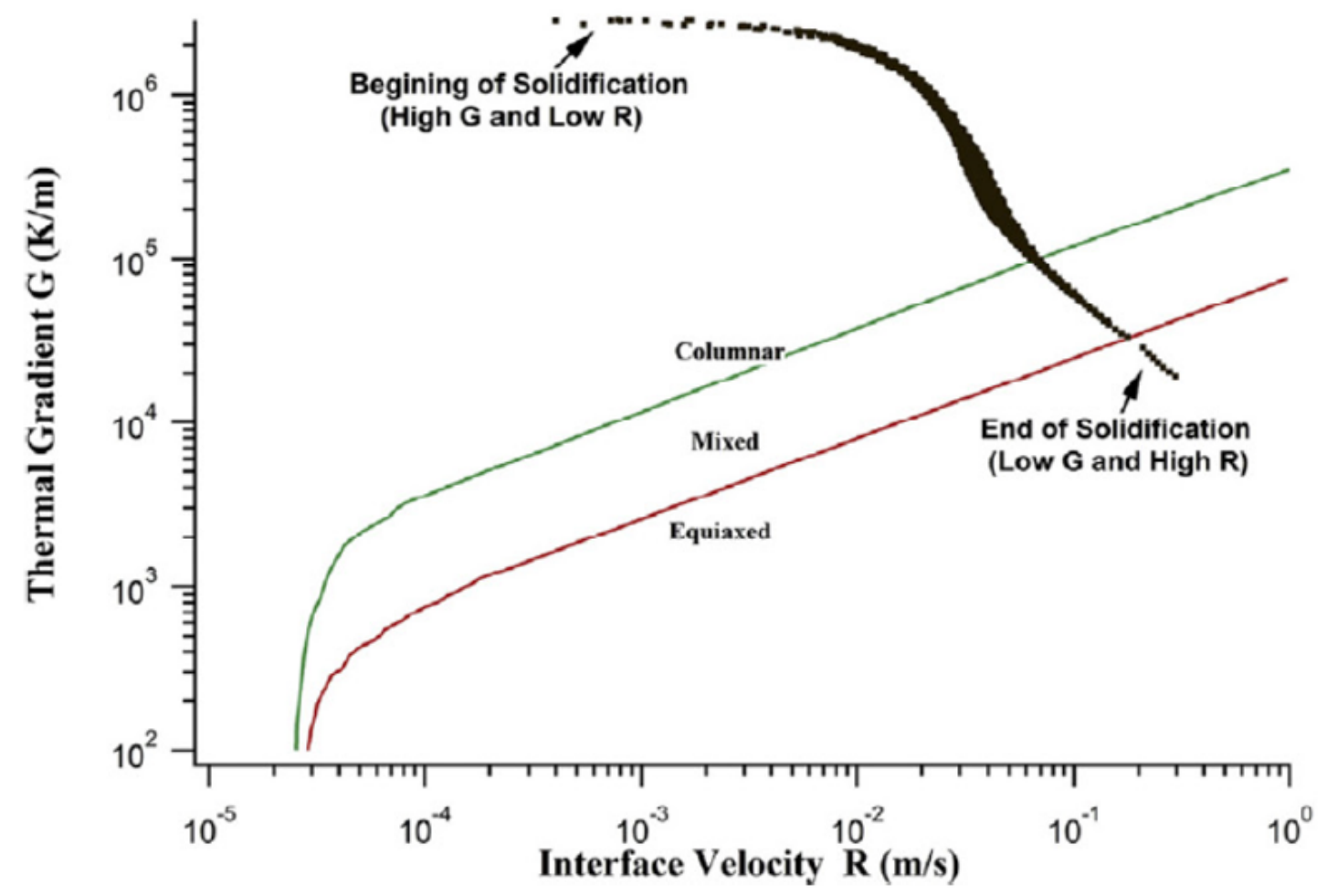

Figure 7: Solidification map of an EBM produced metal showing the formation of columnar and equiaxed grains [43]. 


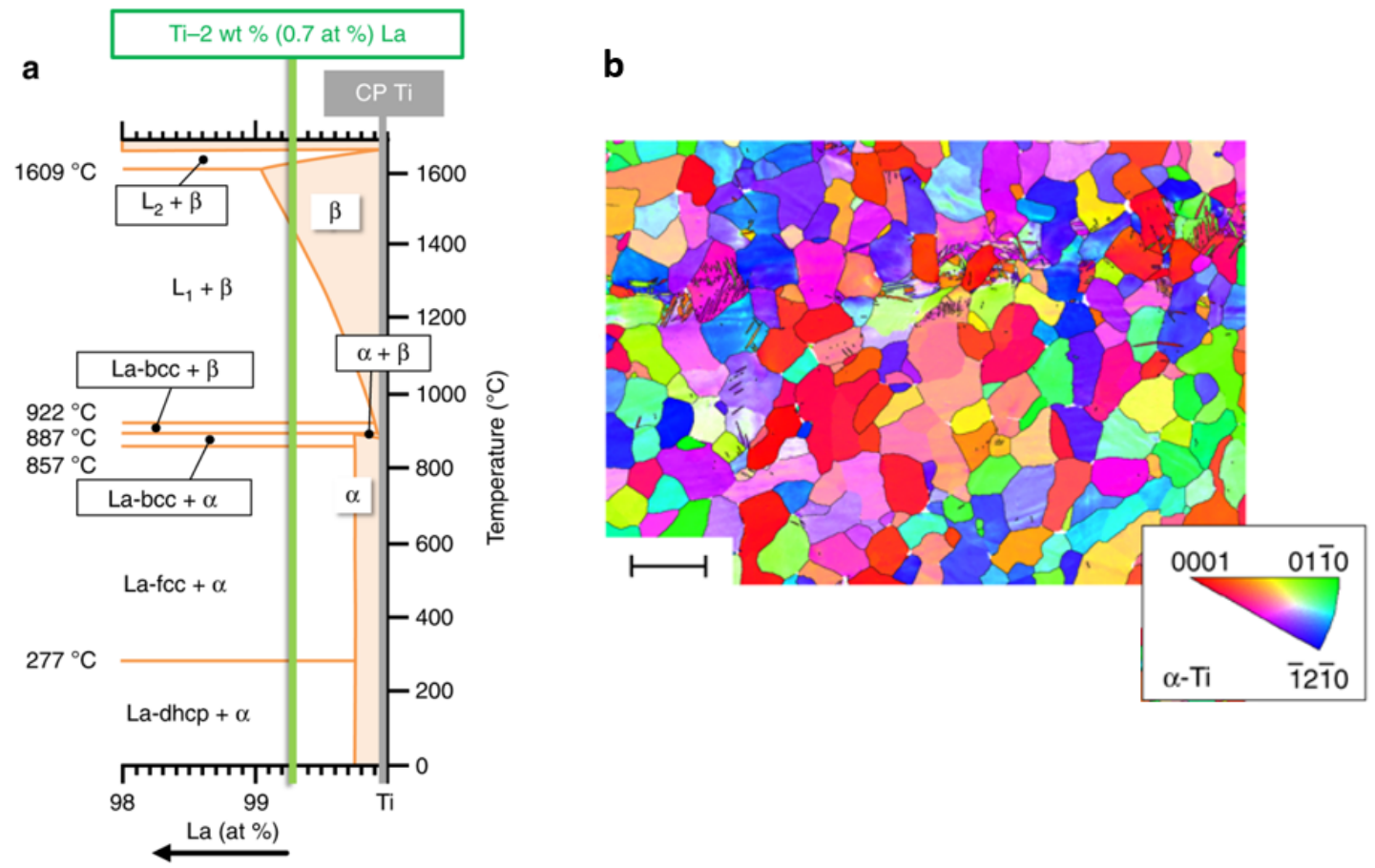

Figure 8: (a) Phase diagram of Ti-La system. (b) Texture-free microstructure after SLM of Ti$2 \mathrm{wt} \%$ La [20].

alloys due to complex thermal cycles in PBF methods. Texture is significantly dependent on scan strategy. Generally, most reported texture after PBF of Ti-6Al-4V is in the $\langle 001\rangle$ direction [22]. But recently, it has been reported that changing the scan strategy can lead to the formation of $\langle 110\rangle$ texture, which increases the yield strength of EBM produced Ti-6Al-4V [45]. Recently, Barriobero-Vila et al. [20] added $2 \mathrm{wt} \%$ La to commercially pure (CP) titanium and produced it via SLM. After SLM, the resulting microstructure consisted of elongated and fine equiaxed $\alpha$ grains without pronounced texture as can be seen in Fig. 8b. The weakening of texture has been attributed to the several phase transformations that occur during processing (Fig. 8a).

\subsection{Build defects}

The most frequently reported build defects in PBF of titanium alloys are porosity and residual stresses. The presence of porosity affects negatively the mechanical properties (tensile strength and ductility) of the as-built component [6]. Porosity can be divided into four categories: pro- 


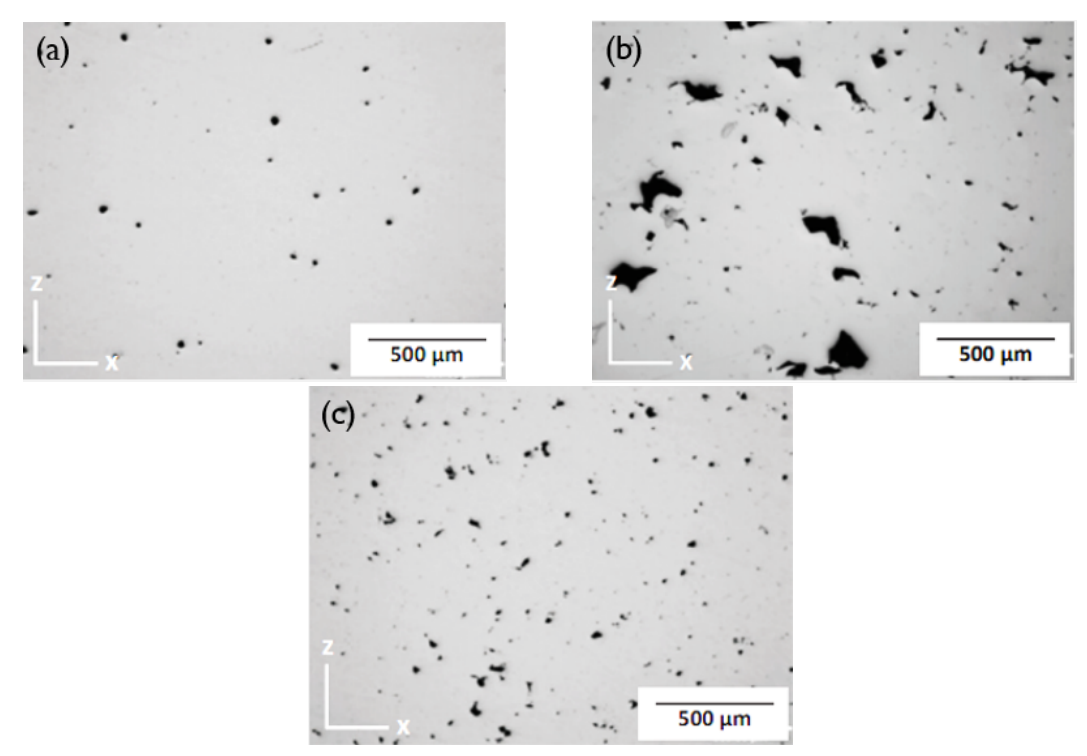

Figure 9: Optical micrographs showing (a) gas entrapped porosity, (b) porosity caused by evaporation and (c) lack of fusion defect [55].

cess induced, gas entrapped (Fig. 9a), evaporation-caused (Fig.9b) and lack of fusion (Fig. 9c) [46, 47, 48, 49, 50]. Gas entrapped porosity are typically spherical and form during gas atomisation [51] or during ALM due to the possibility of reaction of impurities such as oxygen with titanium [52]. Other types of pores are non-spehrical and attributed to either instabilities in the melt pool or insufficient energy density that lead to lack of fusion [53]. It was found that if the pressure around the bubbles within the molten pool is lower than the vapour pressure of the material, the generated bubbles are entrapped during solidification. As a general rule, liquid metal evaporates when its temperature-related saturated vapour pressure reaches its hydraulic pressure and leads to the formation of porosity [54]. Porosity is usually correlated to the processing parameters through energy density. Process-induced porosity can form at low power beam. Evaporation-caused pores form under high power beam conditions. Increase in hatch spacing is also a cause of lack of fusion [6]. A minimum amount of porosity is expected at an intermediate energy density. Therefore controlling the process parameters and powder production is necessary to reach high density titanium alloys.

Residual stress is an internally remaining stress present even after removal of a load, and causes distortion, delamination of the layers during processing and loss of geometric tolerance of the part. 
Residual stresses are one of the most significant problems in SLM of titanium alloys [9]. Rapid heating and cooling cycles cause them, possibly leading to premature failures. As the bottom part of the melt pool cools faster than the upper parts, residual stresses are often oriented with build direction. Residual stresses are dependent on processing parameters (scan strategy and energy density). However, it has been shown that the most efficient way to mitigate the residual stress levels is preheating the powder bed, which is applicable in EBM. Edwards et al. [56] showed that preheating the powder bed to $700^{\circ} \mathrm{C}$ can nearly eliminate residual stresses in Ti-6Al-4V produced part by EBM. Although preheating the powder bed in SLM is very difficult, recently, Ali et al. [9] succeeded to produce Ti-6Al-4V component by SLM with low amounts of residual stresses after applying a preheating temperature of $570{ }^{\circ} \mathrm{C}$. Song et al. [57] have shown that different scan strategies can affect temperature fields in the molten pool of SLM produced Ti-6Al-4V and subsequently influence the residual stresses. They succeded to minimise the residual stresses by optimising scan strategies.

\section{Computational methods for simulation}

Due to the complexity of ALM processes, numerical modelling and simulation methods are employed to assess the effects of process parameters on the evolution of the feedstock melting characteristics and predict the optimised conditions for ALM. Numerical models for predicting the defects and phenomena during and after all ALM processes include: Discrete Element (DE), Monte Carlo (MC), Lattice Boltzmann (LB), Finite Volume (FV), Finite Element (FE), Phase Field (PF) and Cellular Automata (CA). These are applied as schematically shown in Fig. 10.

ALM processes are inherently multi scale, thus a comprehensive model should be able to connect the different length scale phenomena. From a length-scale point of view, models can be divided into three categories: micro- (between nano to micrometre), meso- (micro to millimetre) and macro-scale (millimetre to component scale). The models are grouped by length scale in Fig. 11. Micro-scale models predict the microstructure evolution upon solidification, solid-state 


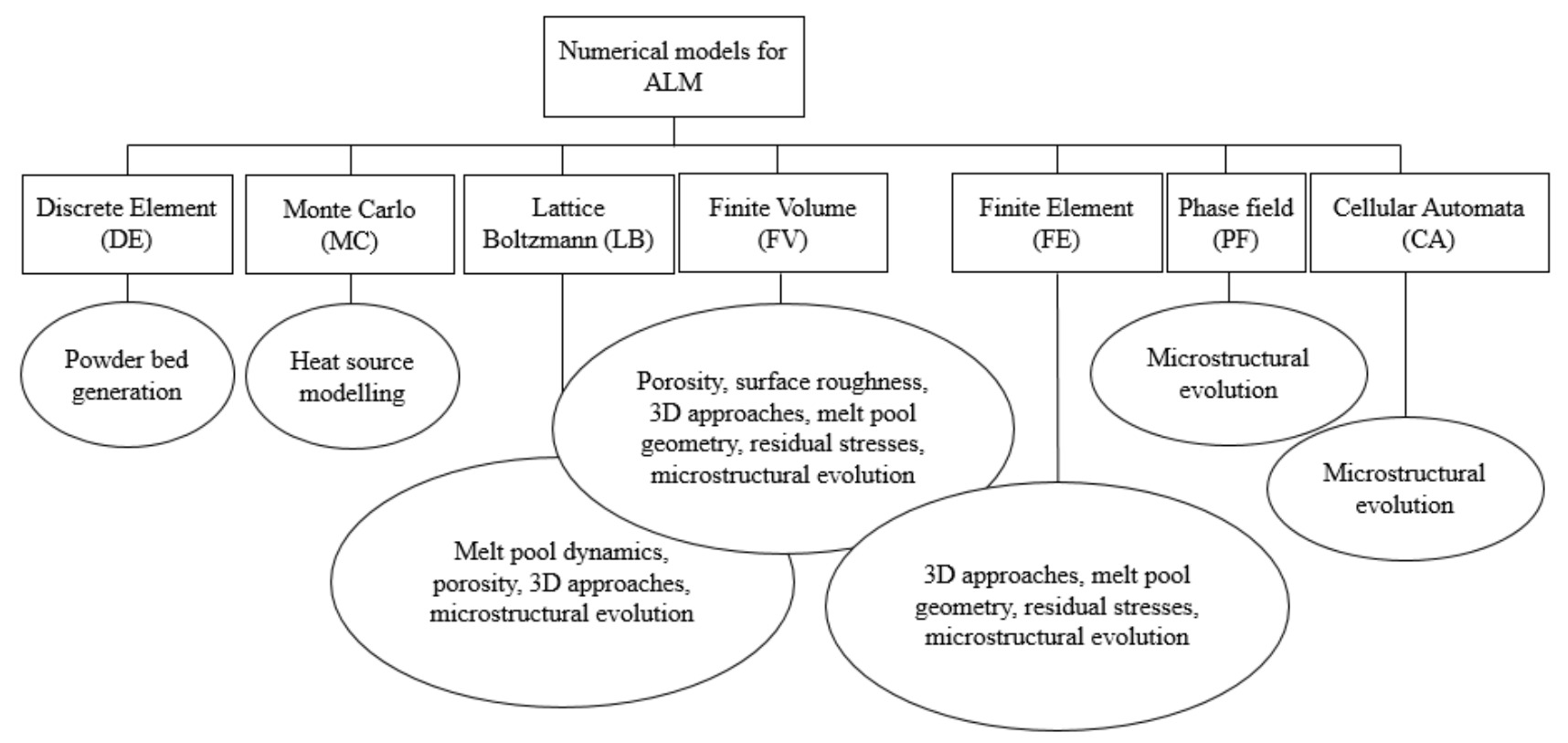

Figure 10: Numerical models for ALM processing and their application.

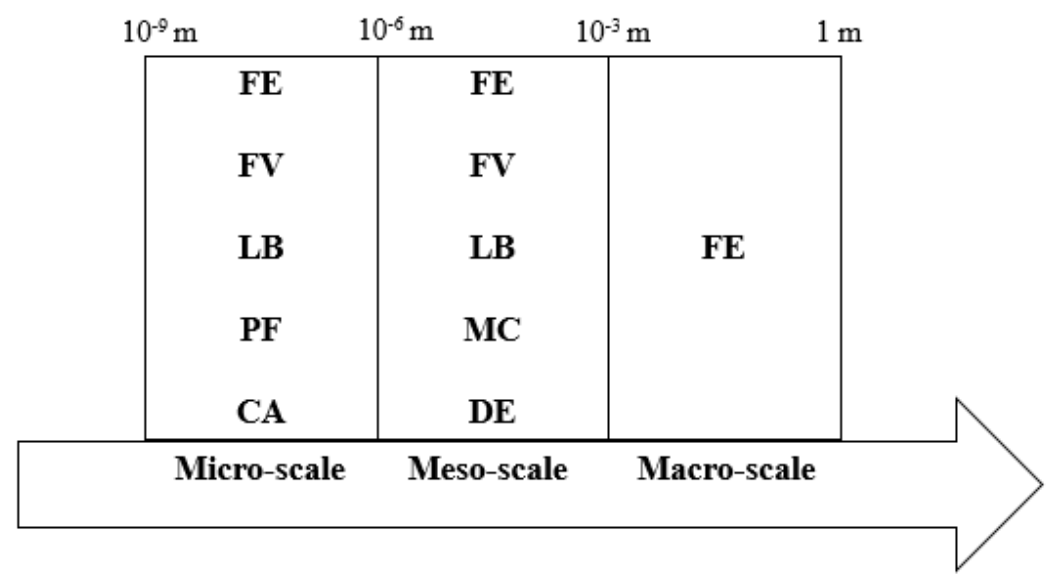

Figure 11: Modelling approaches used for different length scales. 


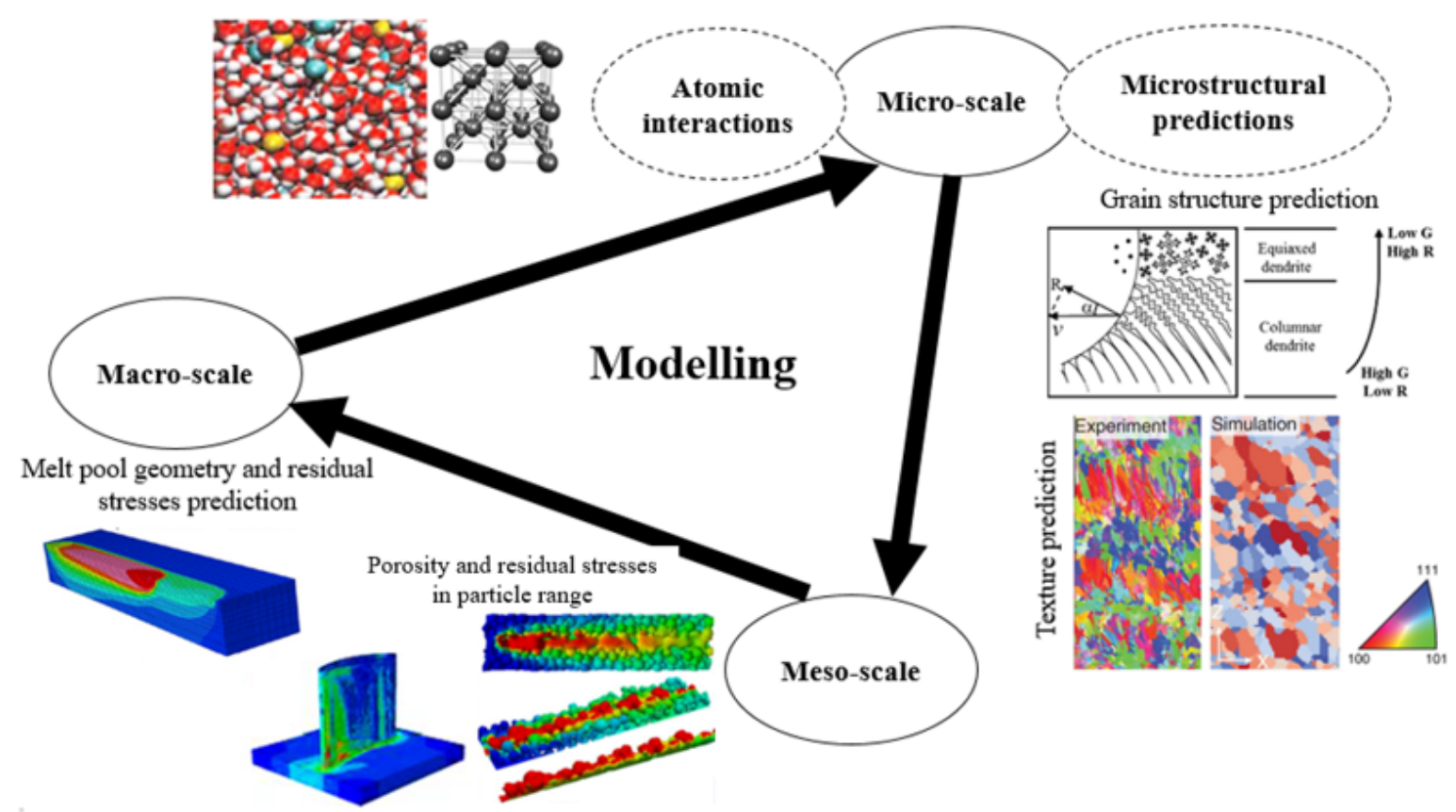

Figure 12: The issues that can be predicted by computational models in different length scales in PBF of titanium alloys.

phase transformations, and grain coarsening. Meso-scale predictions focus on small build volumes addressing issues such as beam-powder interactions, powder consolidation, the simulation of the temperature profiles based on a moving heat source and also the dynamics of phase transformations and fluid flow. At the macro-scale, models include homogeneous thermo-mechanical simulations to assess melt pool geometry and residual stresses of the fabricated parts [58]. As can be seen in Fig. 11, FE methods can be used for simulation at all scales, but methods such as PF and CA focus on microstructural scales. Despite numerous efforts for simulation of different aspects of ALM of metals, there are just a few researches on modelling of PBF methods of titanium alloys. Therefore, there will be a great potential for researchers and industry to focus on understanding PBF of titanium alloys. The issues that have been predicted at different length scales via computational methods during PBF of titanium alloys are illustrated in Fig. 12. It should be noted that the modelling on each length scales is connected to each other. For example, it is impossible to predict the porosity formation in the meso-scale without simulation of the melt pool geometry at the macro-scale. 
In the last part of this review, a summary of the attempts reported in literature to model different aspects of PBF processes for titanium alloys are discussed. The formation and evolution of the melt pool, an analysis of the defects and grain structures after PBF methods have been investigated so far.

\subsection{Melt pool formation simulation}

The SLM technique consists of a complex process of heat and mass transfer including conduction, convection and radiation, which can affect melt pool geometry. The characteristics of the melt pool have a significant effect on the quality of the as-built parts. Efforts have been done to explore the effects of different process parameters on melt pool formation at the macro-scale. Zhuang et al. [59] investigated the effects of important process parameters such as laser power, scanning speed, preheating temperature and hatch spacing between two tracks on melt pool dimensions (width, length and depth) of Ti-6Al-4V powder during SLM, using FE method. FE is a numerical method for solving problems in the fields of heat transfer, fluid flow, and mass transport. Such modelling approach usually uses the Lagrangian framework. The results of their simulation are shown in Fig. 13a-d. They have shown that laser power and scanning speed can affect melt pool dimensions and change in preheating temperature and hatch spacing has no impact on melt pool geometry.

Zhang et al. [54] used FE method for studying the evolution of the melt pool dynamics and geometry during SLM of Ti-6Al-4V with consideration of phase change, recoil pressure (caused by evaporation), surface tension and Marangoni effect (the mass transfer along an interface between two fluids due to a gradient of the surface tension) (Fig. 13e). An ALE (arbitrary LagrangianEulerian) dynamic mesh approach was applied to a track free surface of the molten pool. Their results were also in good agreement with experiment. Using this method, the pressure condition of porosity formation caused by evaporation of alloying elements is studied. This type of porosity may form due to the drop in hydraulic pressure below the temperature-dependent vapour pressure inside the melt pool. Karayagiz et al. [60] also used FE approach to model heat distribution in the melt pool of Ti-6Al-4V during SLM. They found that in addition to process parameters, thermal 
(a)

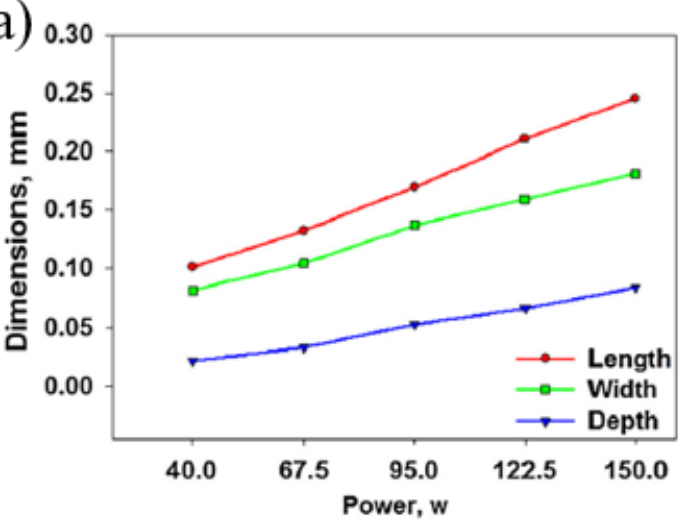

(c)

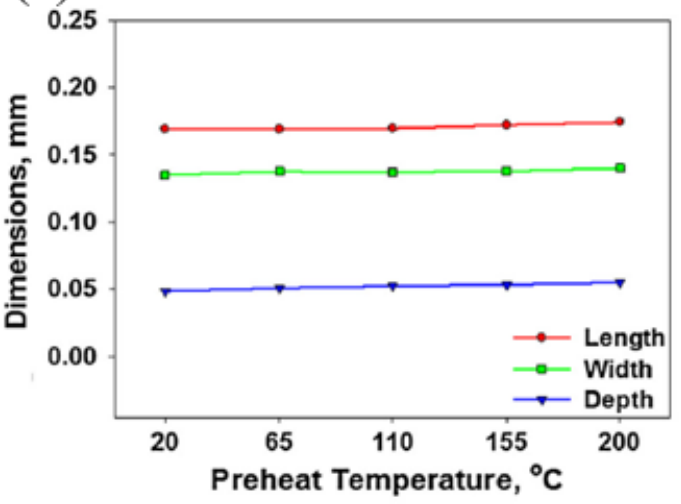

(b) 0

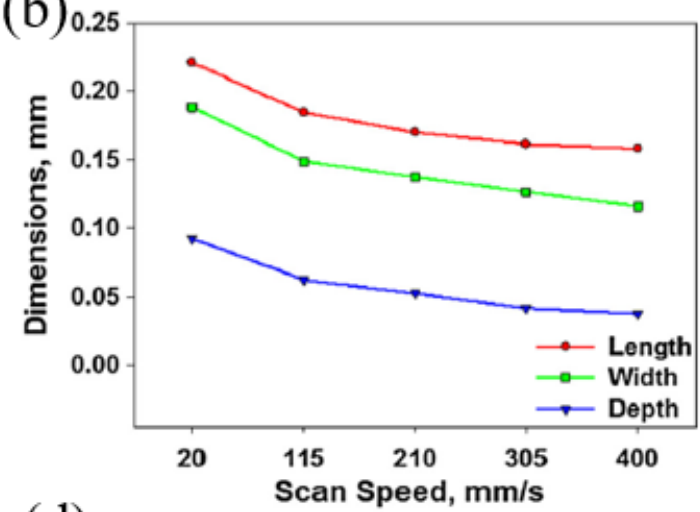

(d)

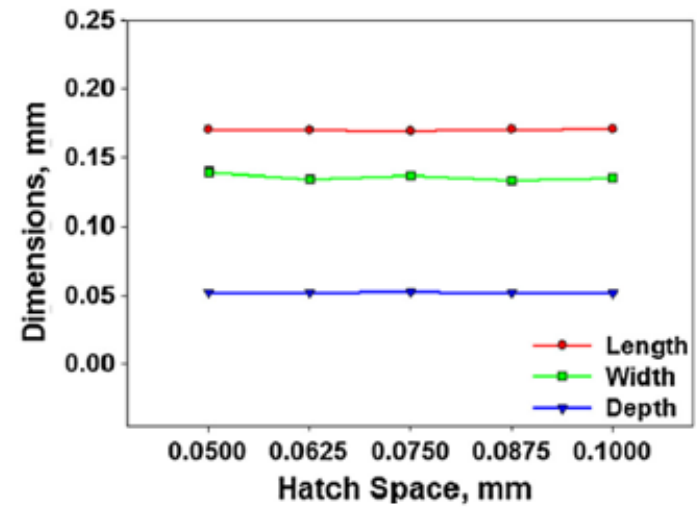

(e)

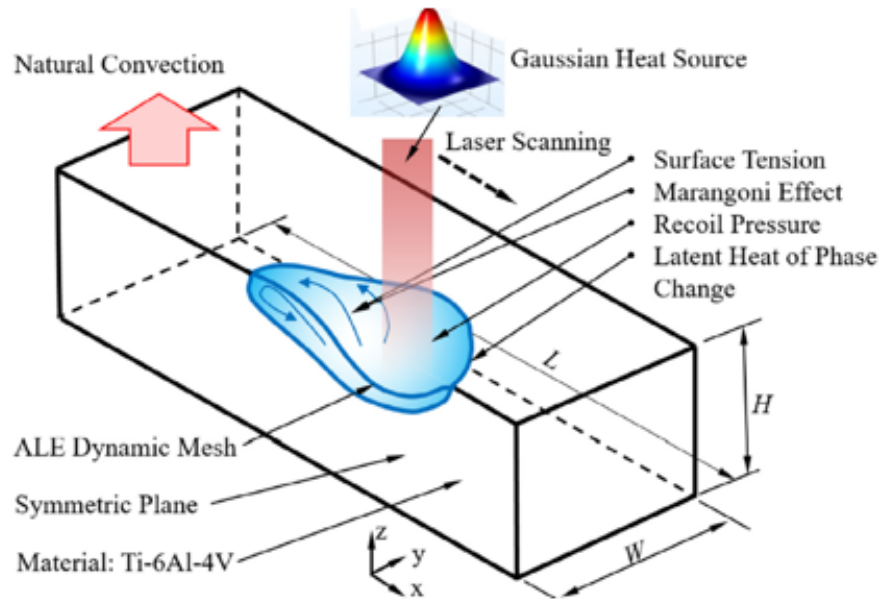

Figure 13: Predictions of melt pool dimensions (width, length and depth) during SLM of Ti-6Al$4 \mathrm{~V}$ with different (a) laser powers; (b) scanning speeds; (c) preheating temperatures; and (d) hatch spacings [59]. (e) Schematics of melt pool simulation [54]. 
conductivity of the liquid phase, porosity level of the powder and absorptivity had also direct influences on the prediction of the melt pool geometry and dynamics. However, as calibration of these parameters is difficult, future investigations are needed.

Recently, interesting work has been done by Li et al. [61], to quantify and predict the melt pool geometry at the meso-scale. They used PF modelling framework to integrate relevant thermal fluid phenomena and elastic structure response, including phase transition, thermal capillarity, interfacial deformation, and thermal stress induced by local laser heating. The results show that the capillary effect plays a significant role for interfacial evolution and solid-liquid phase transition, and helps to bridge the powder and substrate. At the end, the interplay of laser power, spot size of laser, and the scan speed in laser-powder interactions has been demonstrated by the depth of the melt pool.

Compared with SLM, there are less studies on modelling of EBM process. In one of the few attempts in literature, Scharowsky et al. [62] investigated the effects of energy input (given by beam power, scan speed, and hatch spacing) on melt pool formation and loss of aluminum during EBM of Ti-6Al-4V using LB method. They developed process maps dependent on beam power and scan speed for different hatch spacings. They concluded that with increasing scan speed, the energy input decreases and continous melting can be acheived over several beam passes. Thus the maximum temperatures are reduced and evaporation of aluminium is nearly completely suppressed.

\subsection{Microstructure evolution prediction}

The prediction of the SLM microstructure is challenging because of the complex thermal history involving multiple thermal cycles. Yang et al. [63] did a comprehensive study on the microstructural simulation of solidification and solid-state phase transformation processes under various process parameters of SLM using CA method for Ti-6Al-4V. The morphology and size of the $\beta$ grains and martensite was simulated by this model. Based on simulation results, there are three zones: powder melting, remelting and reheating zones; and four stages: powder melting, mushy, multi-phases and solid-state phase transformation stages during SLM of Ti-6Al-4V (Fig. 14). They concluded 

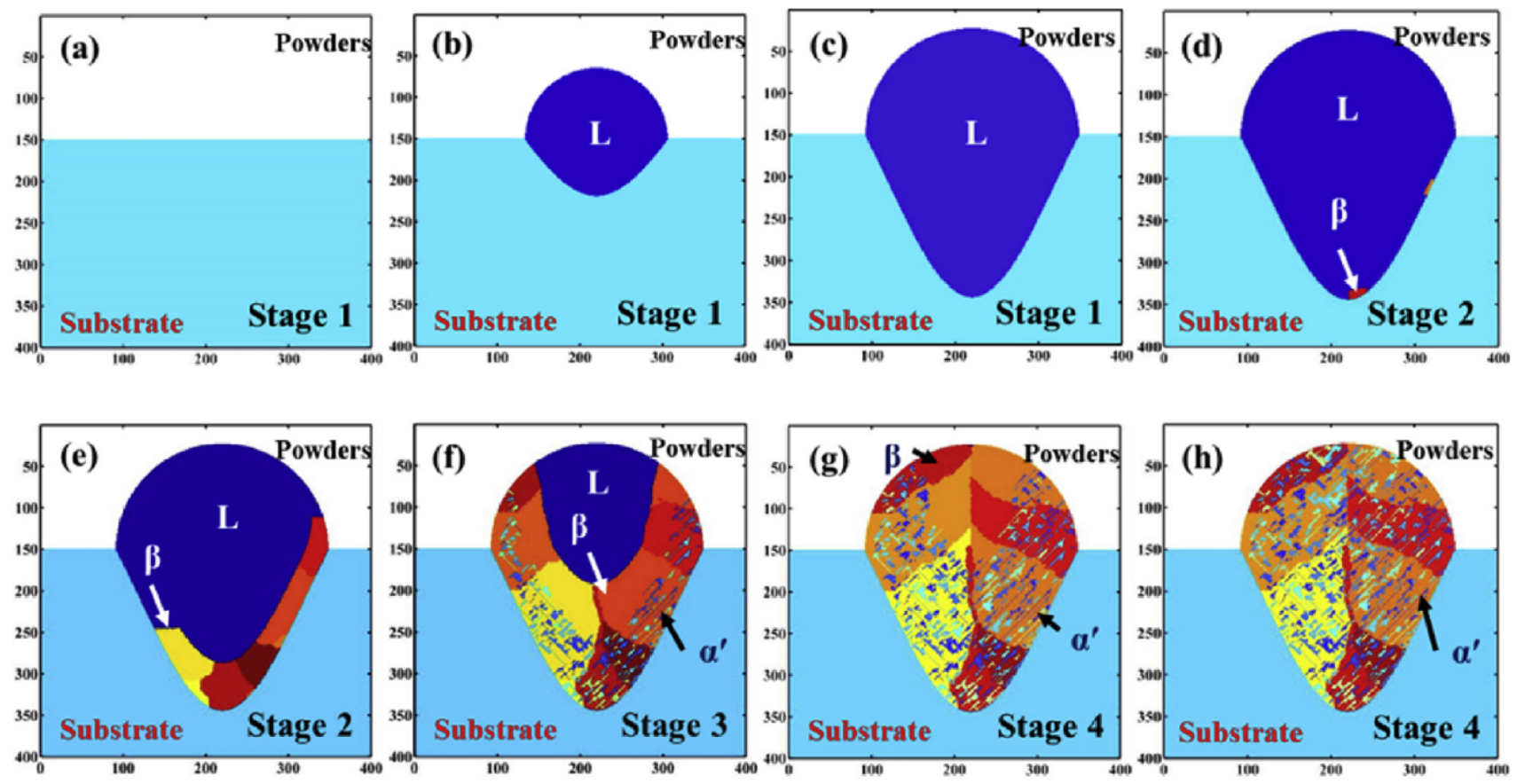

Figure 14: Simulated microstructural evolution of Ti-6Al-4V during SLM; (a)-(c) stage 1 (powder melting), (d) and (e) stage 2 (mushy), (f) stage 3 (multi-phase stage), (g) and (h) stage 4 (solid-state phase transformation) [63].

that the morphology, growth direction and size of $\beta$ grains depend on the direction of heat flux and overlapping of adjacent deposited tracks. Six evolutional types of $\beta$ grains were also introduced during processing.

In the case of EBM process, Liu et al. [64] used a multiscale computational framework which combined macro-scale thermal FE method into meso-scale temperature-dependent grain growth PF model to show the evolution mechanisms of site-specific grain structures during EBM of Ti6Al-4V. In that model, firstly FE method has been used to investigate the thermal distribution and melt pool formation, then the extracted data has been fed into PF model to investigate the grain growth model during EBM. The grain selection, grain nucleation and layer by layer nature of the manufacturing process has been considered in the PF model to fully simulate the process. Grain structure (equiaxed or columnar) and texture development prediction was made in typical thick and thin parts as is shown in Fig. 15. They also succeded to predict the effects of different travel speeds (scan speeds) on the grain structure of the as-built part. 
(a)

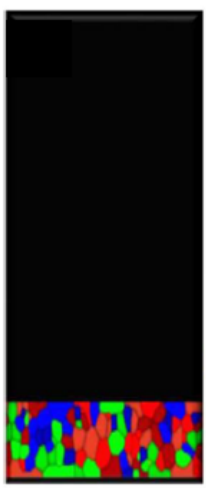

Substrate
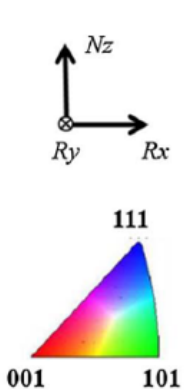

$0.5 \mathrm{~mm}$

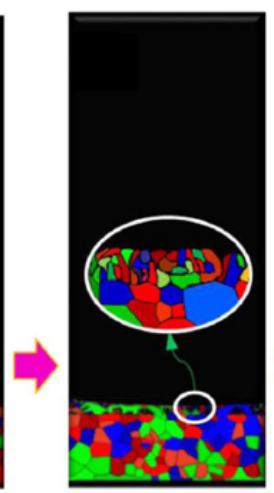

Stage 1

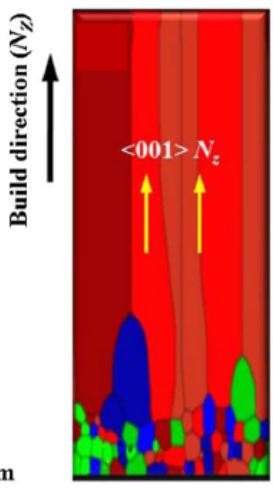

Coarsening $\beta$ grain

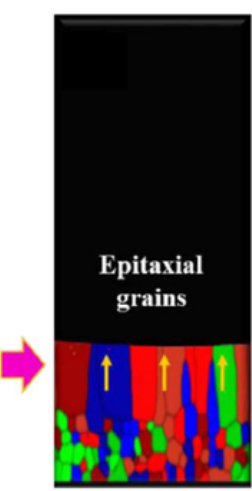

Stage 2
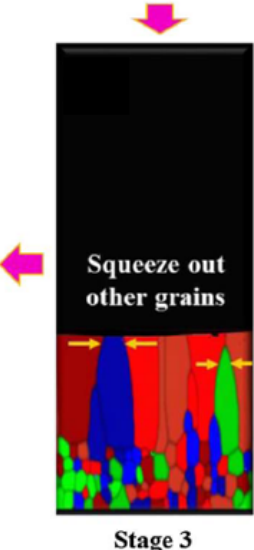

(b)
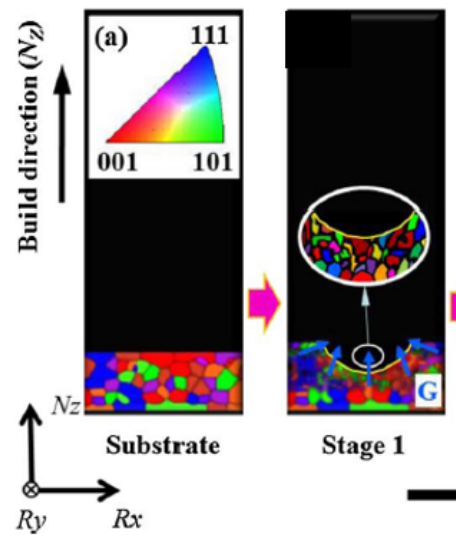

Stage 1

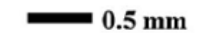

Stage 2

Stage 3

Temperature gradient $(\mathrm{K} / \mathrm{m})$

(c)

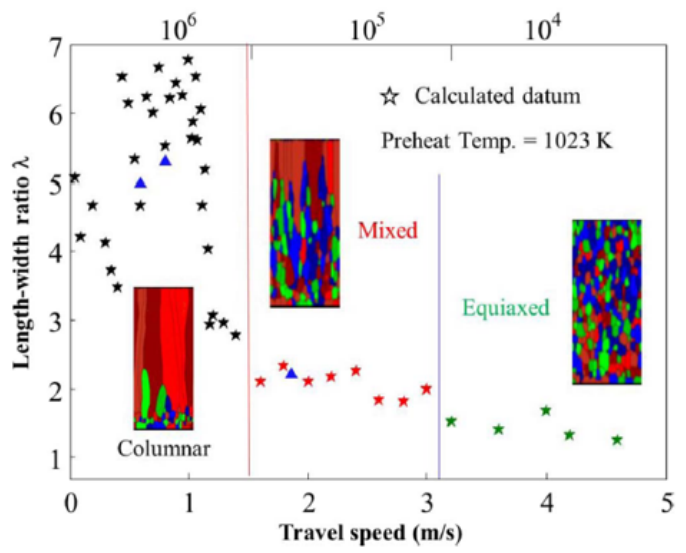

Figure 15: (a) Simulated grain structures and textures of a thick part at different deposition times. A three-stage grain growth behavior can be shown to achieve $\beta$ columnar grains with $\langle 001\rangle$ direction. Stage 1: fine equiaxed grains with random grain orientation formed on top of the substrate; stage 2: columnar grains oriented slightly towards build direction; stage 3: crystallographically favored $\langle 001\rangle$ grains squeeze out other grains. (b) Simulated grain structures and textures of a thin part at different deposition times. A three-stage grain structure formation observed. Stage 1: equiaxed grains near the boundaries od melt pool; stage 2: competitive epitaxial growth amoung different series due to diverse and dispersive thermal gradients $(\mathrm{G})$ along pool edge; stage 3: textured $\langle 001\rangle$ grains prevalent along the central line and invard slanted columnar grains with various grain orientations. (c) The effect of travel (scan) speed on transition of grain structures, the aspect ratio of the grains and temperature gradient. Blue triangles are experimental results and stars show the simulation results [64]. 
Sahoo et al. [65] also simulated the microstructural evolution of Ti-6Al-4V alloy during EBM using PF method. As in formation of microstructure in EBM, temperature gradient and beam scan speed play an important role, the focus of their model was on the effects of these parameters on the dendritic microstructure formation after solidification. Based on their model, columnar dendritic arm spacing and dendritic width decreases with increase in temperature gradient and the beam scan speed, which are in good agreement with the experimental results. Therefore, PF method is a powerful tool for micro-scale simulation of EBM process. However, it is obvious that further research is needed to better understand both SLM and EBM processes of production of titanium alloys at the micro-scale.

\subsection{Porosity and residual stress simulations}

As is discussed in section 4, porosity can be formed due to unoptimised process parameters. As process parameters affect the geometry of the melt pool, therefore for minimising porosity in PBF of titanium alloys, efforts have been made to optimise process parameters and subsequently the melt pool geometry. Panwisawas et al. [66] used thermal fluid dynamics to study pore evolution during SLM of Ti-6Al-4V. The results show that the pore morphology can change from near spherical to elongated shape with increase in laser scan speed. They also predicted the threshold for laser scan speed in order to avoid porosity after SLM (Fig. 16a). In another research, Klassen et al. [67] proposed an LB model for prediction of evaporation or loss of elements, which can lead to formation of porosity during EBM of Ti-6Al-4V. Their model solved the hydrodynamics and thermodynamics of the melt pool. The results of the effects of laser power on mass loss of Ti-6Al-4V has been shown in Fig. 16b. Therefore, by optimising process parameters, porosity can be controlled, but there are not many works that have been done on prediction of porosities in PBF of titanium alloys.

Understanding and prediction of residual stresses in SLM of titanium alloys is significant, especially in safety-critical applications. Since experimental measurement during processing is not practical, a validated model capable of reliably simulating these stresses is extremely valuable. To 


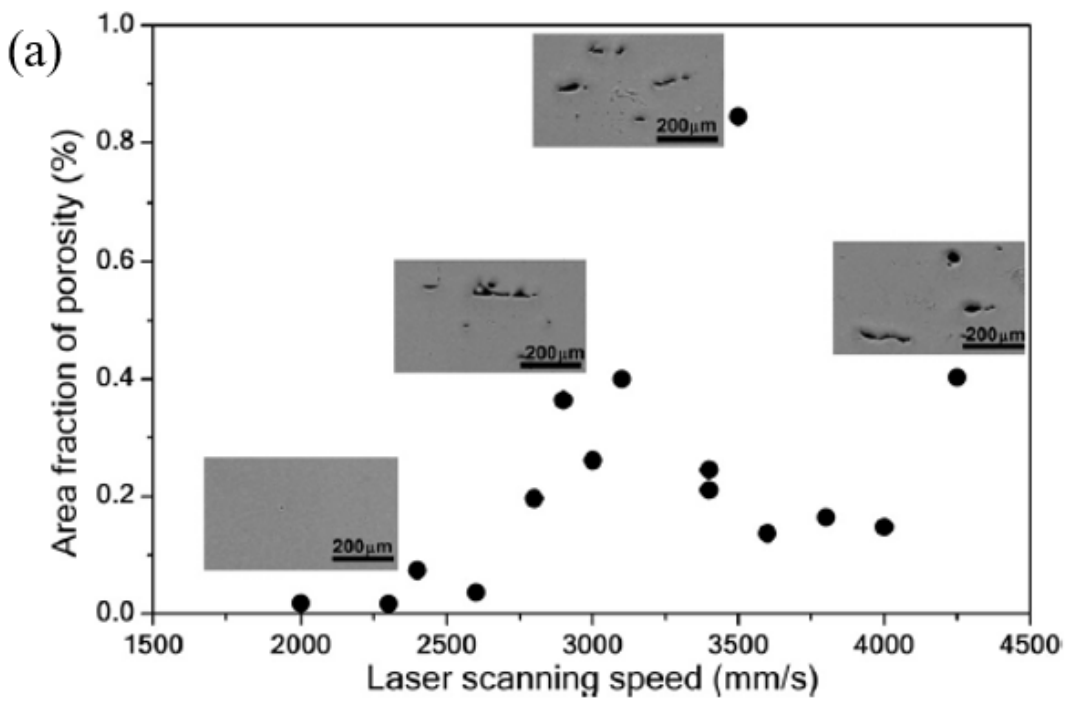

(b)

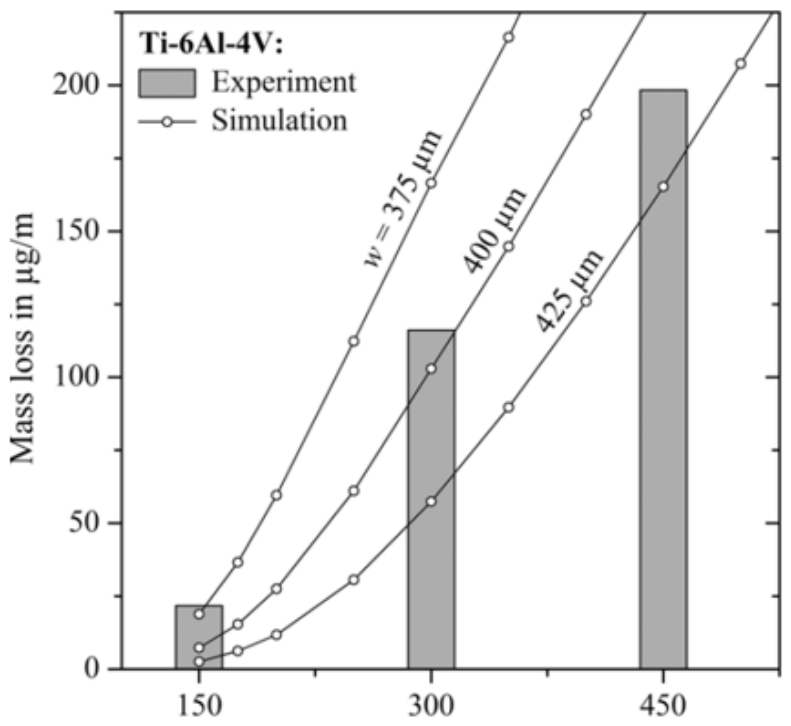

Figure 16: (a) Area fraction of porosity variation with laser scanning speeds using a constant laser power [66]. (b) Mass loss of Ti-6Al-4V due to evaporation for different electron beam powers at a constant energy input. $w$ shows the beam width [67]. 
this end, a thermo-mechanical model (a highly parallelised multi-physics FE code) has been evaluated [68]. To provide validation data for this model, Strantza et al. [69] performed energy dispersive diffraction to measure the lattice parameters and determine the elastic strains and stresses in SLM of Ti-6Al-4V. The simulation results were in good agreement with experimental measurements (Fig. 17). Kapoor et al. [70] investigated residual stresses in Ti-6Al-4V produced by SLM via implementing crystal plasticity FE simulations and high resolution digital image correlation on samples subjected to cyclic loading. A method to incorporate the effect of grain-level residual stresses via geometrically necessary dislocations is developed and implemented within the crystal plasticity FE framework. Simulation results showed that prior $\beta$ boundaries play an important role in strain localisation. Consequently possible sites for damage nucleation were predicted to be the regions of high plastic strain accumulation. Combinig macro- and meso-scale methods, Ali et al. [71] presented a new modelling approach to simulate the temperature distribution during SLM of

Ti-6Al-4V, as well as the resulting melt pool geometry, solidification behavior, cooling rates and temperature gradients which led to prediction of residual stress build-up. An enhanced laser penetration approach was used to account for heat transfer in melt pool due to Marangoni convection. The model was capable of predicting the different solidification behavior responsible for residual stresses in SLM as-built part. The model-predicted trends in cooling rates and temperature gradients for different SLM processing parameters correlated with experimentally measured residual stress trends.

\section{Conclusions and suggestions for future work}

The principal processes related to powder bed fusion additive layer manufacturing of titanium alloys have been reviewed. This includes powder production to post-processing. Numerical models that have been used for the simulation and the resulting prediction of powder bed fusion processing and component properties are also incorporated.

Powder bed fusion methods need further development to become cost-effective. The unique mi- 

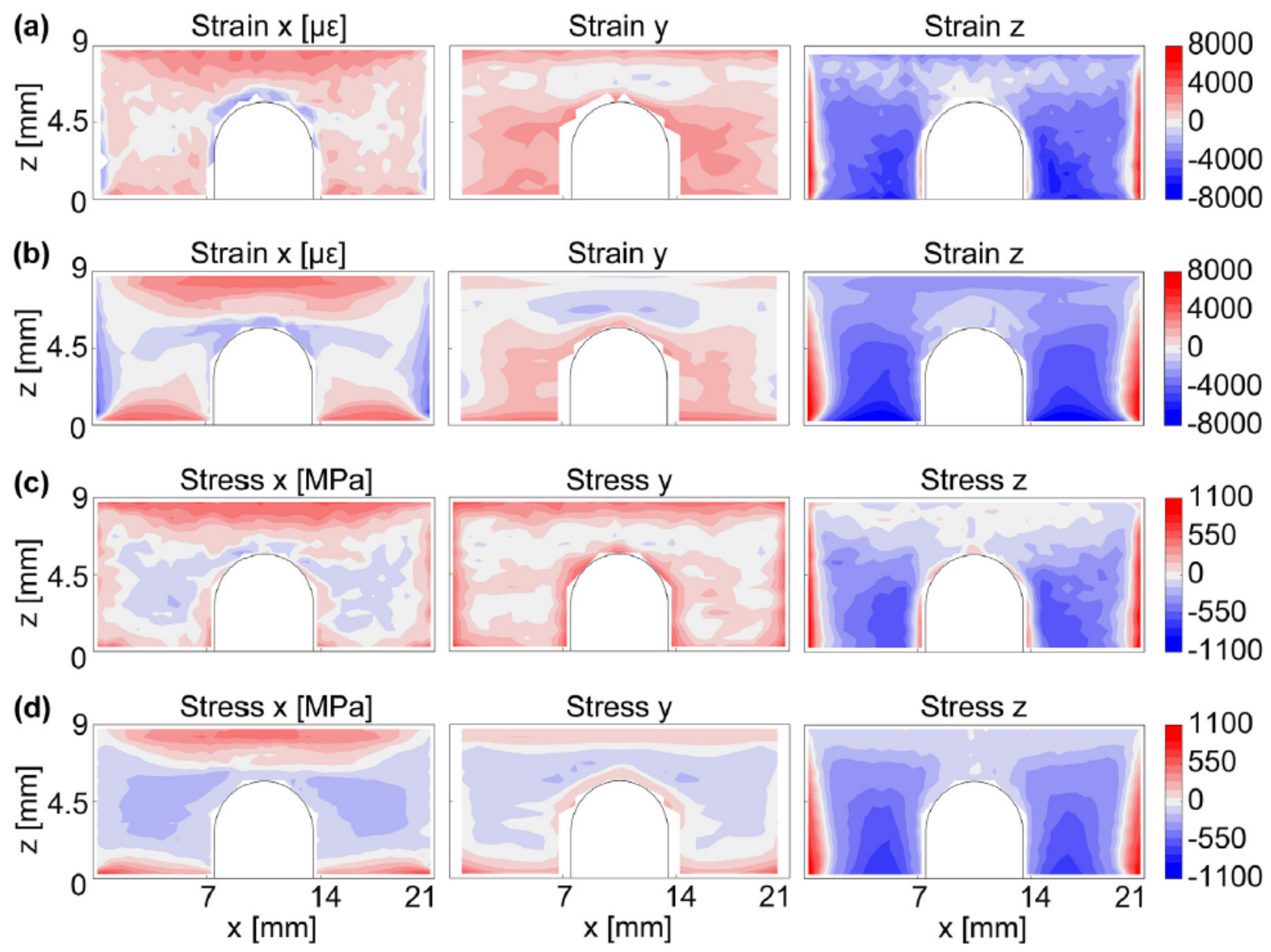

Figure 17: Contour plots of the middle cross section of the SLM produced Ti-6Al-4V specimens for $\mathrm{x}, \mathrm{y}$ and $\mathrm{z}$ directions. (a) Experimental residual strain, (b) simulated residual strain, (c) experimental residual stress and (d) simulated residual stress [69]. 
crostructures resulting from powder bed fusion are suitable candidates for some titanium alloys components. Two main challenges have been identified and addressed in this review: understanding the definition of a good powder feedstock, and its relationship with powder manufacturing processes, as well as understanding the microstructure developed during the powder bed fusion processes.

Reducing the cost of the powder production methods can play a crucial role in lowering the expenses of the whole manufacturing process. Newer and lower cost powder production methods such as granulation-sintering-deoxygenation have a great potential for future investigation. Increasing the quality of the produced powders leads to the better mechanical properties, less powder defects reduces the need for post-processing after powder bed fusion. There must be a balance between cost and quality of powder production. What increases the complexity of powder production for powder bed fusion is that there are no specifications for powder bed fusion quality requirements. Therefore, in future more research should be performed to systematically identify the powder properties that have significant impact on its performance, both for spreading as well as for how the powder responds to the melting process. These studies will evolve into specifications that can describe and control the process variables of powders used for powder bed fusion.

Despite significant improvements in understanding and solving the powder bed fusion process challenges, mass-industrialisation of such technology requires it to become faster and more reliable. So far, only selective laser melting can be used in industry due to limited applications and materials. In comparison with selective laser melting, electron beam melting technology is currently far from being completely developed. In the case of titanium alloys the focus of literature has been on the development and optimisation of Ti-6Al-4V. In the near future, the variety of additive layer manufactured titanium alloys can be further increased. Materials with better mechanical properties must be produced by powder bed fusion, adopting design methods for optimising chemical composition. The combination and optimisation of the unique properties of powder bed fusion produced parts with enhanced mechanical properties can lead to the development of alloys with exceptional performance and can increase the application of titanium alloys. 
A suggestion for future application of powder bed fusion processes is to increase the melting and production rates, with direct effects in cost reduction and yield. This may be possible by increasing the number of heat sources, e.g. the number of laser beams in an selective laser melting machine. Increasing machine reliability and decreasing the role of the operator can lead to an increase in production rates.

For the prediction of powder bed fusion processing, different modelling approaches have been in-

troduced. However, most of these models only can investigate one or two specific issues related to the defects or mechanical properties of powder bed fusion produced parts. Using finite element approaches, more variables can be predicted and modelled. Moreover, there are a few approaches for studying microstructural evolution and defect prediction during selective laser melting and electron beam melting of titanium alloys. Issues such as grain formation and growth, in situ heat treatments during powder bed fusion and solid state phase transformations should be further considered in future work.

\section{Acknowledgement}

The author is grateful to LPW Technology for useful discussions, and to the Royal Academy of Engineering for funding.

\section{References}

[1] Murr LE, Gaytan SM, Ramirez DA, et al. Metal fabrication by additive manufacturing using laser and electron beam melting technologies. Mater Sci Tech. 2012;28:1-14.

[2] Galindo-Fernández M, Mumtaz K, Rivera-Díaz-del Castillo P, et al. A microstructure sensitive model for deformation of ti-6al-4v describing cast-and-wrought and additive manufacturing morphologies. Mater Des. 2018;160:350-362. 
[3] Powder Metallurgy Methods and Applications. ASM Handbook, Volume 7, Powder Metallurgy; 2015.

[4] Galati M, Iuliano L. A literature review of powder-based electron beam melting focusing on numerical simulations. Addit Manuf. 2018;19:1-20.

[5] Murr L. Metallurgy of additive manufacturing: Examples from electron beam melting. Addit Manuf. 2015;5:40-53.

[6] DebRoy T, Wei H, Zuback J, et al. Additive manufacturing of metallic components - Process, structure and properties. Prog Mater Sci. 2018;92:112-224.

[7] An overview of powder granulometry on feedstock and part performance in the selective laser melting process. Addit Manuf. 2017;18:228-255.

[8] Gu DD, Meiners W, Wissenbach K, et al. Laser additive manufacturing of metallic components: materials, processes and mechanisms. Int Mater Rev. 2012;57(3):133-164.

[9] Ali H, Ma L, Ghadbeigi H, et al. In-situ residual stress reduction, martensitic decomposition and mechanical properties enhancement through high temperature powder bed pre-heating of Selective Laser Melted Ti6Al4V. Mater Sci Eng, A. 2017;695:211-220.

[10] Körner C. Additive manufacturing of metallic components by selective electron beam melting — a review. Int Mater Rev. 2016;61(5):361-377.

[11] Yap CY, Chua CK, Dong ZL, et al. Review of selective laser melting: Materials and applications. Appl Phys Rev. 2015;2(4):041101.

[12] Hao YL, Li SJ, Yang R. Biomedical titanium alloys and their additive manufacturing. Rare Met. 2016;35(9):661-671.

[13] Rack H, Qazi J. Titanium alloys for biomedical applications. Mater Sci Eng, C. 2006; 26(8):1269-1277. 
[14] Wang M, Lin X, Huang W. Laser additive manufacture of titanium alloys. Mater Technol. $2016 ;: 1-8$.

[15] Kruth J, Mercelis P, Van Vaerenbergh J, et al. Binding mechanisms in selective laser sintering and selective laser melting. Rapid Prototyp J. 2005;11(1):26-36.

[16] Vandenbroucke B, Kruth J. Selective laser melting of biocompatible metals for rapid manufacturing of medical parts. Rapid Prototyp J. 2007;13(4):196-203.

[17] Zhang L, Klemm D, Eckert J, et al. Manufacture by selective laser melting and mechanical behavior of a biomedical Ti-24Nb-4Zr-8Sn alloy. Scr Mater. 2011;65(1):21-24.

[18] Liu Y, Wang H, Li S, et al. Compressive and fatigue behavior of beta-type titanium porous structures fabricated by electron beam melting. Acta Mater. 2017;126:58-66.

[19] Li GC, Li J, Tian XJ, et al. Microstructure and properties of a novel titanium alloy Ti-6Al-2V1.5Mo-0.5Zr-0.3Si manufactured by laser additive manufacturing. Mater Sci Eng A. 2017; 684:233-238.

[20] Barriobero-Vila P, Gussone J, Stark A, et al. Peritectic titanium alloys for 3D printing. Nat Commun. 2018;9(1):3426.

[21] Frazier WE. Metal Additive Manufacturing: A Review. J Mater Eng Perform. 2014; 23(6):1917-1928.

[22] Zhu Y, Tian X, Li J, et al. The anisotropy of laser melting deposition additive manufacturing of Ti-6.5Al-3.5Mo-1.5Zr-0.3Si titanium alloy. Mater Des. 2015;67:538-542.

[23] Ter Haar GM, Becker T, Blaine DC. Influence of heat treatments on the microstructure and tensile behavior of selective laser melting-produced TI-6AL-4V parts. S Afr J Ind Eng. 2016; 27(3):174-183. 
[24] Antonysamy A, Meyer J, Prangnell P. Effect of build geometry on the $\beta$-grain structure and texture in additive manufacture of Ti6Al4V by selective electron beam melting. Mater Charact. $2013 ; 84: 153-168$.

[25] Sun P, Fang ZZ, Zhang Y, et al. Review of the Methods for Production of Spherical Ti and Ti Alloy Powder. JOM. 2017;69(10):1853-1860.

[26] Kaplan AFH, Powell J. Spatter in laser welding. J Laser Appl. 2011;23(3):032005.

[27] Tang HP, Qian M, Liu N, et al. Effect of Powder Reuse Times on Additive Manufacturing of Ti-6Al-4V by Selective Electron Beam Melting. JOM. 2015;67(3):555-563.

[28] Dawes J, Bowerman R, Trepleton R. Introduction to the Additive Manufacturing Powder Metallurgy Supply Chain. Johnson Matthey Technol Rev. 2015;59(3):243-256.

[29] Wei M, Chen S, Liang J, et al. Effect of atomization pressure on the breakup of TA15 titanium alloy powder prepared by EIGA method for laser 3D printing. Vacuum. 2017;143:185-194.

[30] Peter W, Committee AIH. ASM Handbook: Volume 7: Powder Metal Technologies and Applications; 1998.

[31] Gerling R, Clemens H, Schimansky F. Powder Metallurgical Processing of Intermetallic Gamma Titanium Aluminides. Adv Eng Mater. 2004;6(12):23-38.

[32] Sun P, Fang ZZ, Xia Y, et al. A novel method for production of spherical Ti-6Al-4V powder for additive manufacturing. Powder Technol. 2016;301:331-335.

[33] Doblin C, Freeman D, Richards M. The TiRO ${ }^{\mathrm{TM}}$ Process for the Continuous Direct Production of Titanium Powder. Key Eng Mater. 2013;551:37-43.

[34] Özbilen S. Satellite formation mechanism in gas atomised powders. Powder Metall. 1999; 42(1):70-78. 
[35] Yolton C, Froes FH. Conventional titanium powder production. Titanium Powder Metall. $2015 ;: 21-32$.

[36] Chen G, Zhao S, Tan P, et al. A comparative study of Ti-6Al-4V powders for additive manufacturing by gas atomization, plasma rotating electrode process and plasma atomization. Powder Technol. 2018;333:38-46.

[37] Herzog D, Seyda V, Wycisk E, et al. Additive manufacturing of metals. Acta Mater. 2016; 117:371-392.

[38] Mayer D, Stoffregen HA, Heuss O, et al. Additive manufacturing of active struts for piezoelectric shunt damping. J Intell Mater Syst Struct. 2016;27(6):743-754.

[39] Parsa A, Ramsperger M, Kostka A, et al. Transmission Electron Microscopy of a CMSX-4 Ni-Base Superalloy Produced by Selective Electron Beam Melting. Metals. 2016;6(11):258 .

[40] Kok Y, Tan X, Wang P, et al. Anisotropy and heterogeneity of microstructure and mechanical properties in metal additive manufacturing: A critical review. Mater Des. 2018;139:565-586.

[41] Gibson I, Rosen DW, Stucker B. Design for additive manufacturing. In: Additive manufacturing technologies. Springer; 2010. p. 299-332.

[42] Qiu C, Adkins NJ, Attallah MM. Microstructure and tensile properties of selectively lasermelted and of HIPed laser-melted Ti-6Al-4V. Mater Sci Eng A. 2013;578:230-239.

[43] Raghavan N, Dehoff R, Pannala S, et al. Numerical modeling of heat-transfer and the influence of process parameters on tailoring the grain morphology of IN718 in electron beam additive manufacturing. Acta Mater. 2016;112:303-314.

[44] Kumar P, Prakash O, Ramamurty U. Micro-and meso-structures and their influence on mechanical properties of selectively laser melted Ti-6Al-4V. Acta Mater. 2018;154:246-260. 
[45] Hrabe N, White R, Lucon E. Effects of internal porosity and crystallographic texture on charpy absorbed energy of electron beam melting titanium alloy (ti-6al-4v). Mater Sci Eng A. 2019;742:269-277.

[46] Vandenbroucke B, Kruth J. Selective laser melting of biocompatible metals for rapid manufacturing of medical parts. Rapid Prototyp J. 2007;13(4):196-203.

[47] Thijs L, Verhaeghe F, Craeghs T, et al. A study of the microstructural evolution during selective laser melting of Ti-6Al-4V. Acta Mater. 2010;58(9):3303-3312.

[48] Tammas-Williams S, Zhao H, Léonard F, et al. XCT analysis of the influence of melt strategies on defect population in Ti-6Al-4V components manufactured by Selective Electron Beam Melting. Mater Charact. 2015;102:47-61.

[49] Brice CA, Rosenberger BT, Sankaran SN, et al. Chemistry Control in Electron Beam Deposited Titanium Alloys. Mater Sci Forum. 2009;618-619:155-158.

[50] Gaytan SM, Murr LE, Medina F, et al. Advanced metal powder based manufacturing of complex components by electron beam melting. Mater Technol. 2009;24(3):180-190.

[51] Bauereiß A, Scharowsky T, Körner C. Defect generation and propagation mechanism during additive manufacturing by selective beam melting. Journal of Materials Processing Technology. 2014;214(11):2522-2528.

[52] Kruth JP, Badrossamay M, Yasa E, et al. Part and material properties in selective laser melting of metals. In: Proceedings of the 16th international symposium on electromachining; 2010.

[53] Zhao C, Fezzaa K, Cunningham RW, et al. Real-time monitoring of laser powder bed fusion process using high-speed x-ray imaging and diffraction. Sci Rep. 2017;7(1):3602.

[54] Zhang T, Li H, Liu S, et al. Evolution of molten pool during selective laser melting of ti-6al4v. J Phys D: Appl Phys. 2018;52(5):055302. 
[55] LPW Case Study Examines Porosity in Metal 3D Printing, Helps Users Optimize New System - 3DPrint.com — The Voice of 3D Printing / Additive Manufacturing ; 2018.

[56] Edwards P, O'conner A, Ramulu M. Electron beam additive manufacturing of titanium components: properties and performance. J Manuf Sci Eng. 2013;135(6):061016.

[57] Song J, Wu W, Zhang L, et al. Role of scanning strategy on residual stress distribution in ti-6al-4v alloy prepared by selective laser melting. Optik. 2018;170:342-352.

[58] Sames WJ, List FA, Pannala S, et al. The metallurgy and processing science of metal additive manufacturing. Int Mater Rev. 2016;61(5):315-360.

[59] Zhuang JR, Lee YT, Hsieh WH, et al. Determination of melt pool dimensions using doefem and rsm with process window during slm of ti6al4v powder. Opt Laser Technol. 2018; 103:59-76.

[60] Karayagiz K, Elwany A, Tapia G, et al. Numerical and experimental analysis of heat distribution in the laser powder bed fusion of ti-6al-4v. IISE Trans. 2018;:1-17.

[61] Li JQ, Fan TH. Phase-field modeling of metallic powder-substrate interaction in laser melting process. Int J Heat Mass Transfer. 2019;133:872-884.

[62] Scharowsky T, Bauereiß A, Körner C. Influence of the hatching strategy on consolidation during selective electron beam melting of ti-6al-4v. Int J Adv Manuf Technol. 2017;92(58):2809-2818.

[63] Yang J, Yu H, Yang H, et al. Prediction of microstructure in selective laser melted ti6al4v alloy by cellular automaton. J Alloys Compd. 2018;748:281-290.

[64] Liu P, Ji Y, Wang Z, et al. Investigation on evolution mechanisms of site-specific grain structures during metal additive manufacturing. J Mater Process Technol. 2018;257:191-202.

[65] Sahoo S, Chou K. Phase-field simulation of microstructure evolution of ti-6al-4v in electron beam additive manufacturing process. Addit Manuf. 2016;9:14-24. 
[66] Panwisawas C, Qiu C, Sovani Y, et al. On the role of thermal fluid dynamics into the evolution of porosity during selective laser melting. Scr Mater. 2015;105:14-17.

[67] Klassen A, Scharowsky T, Körner C. Evaporation model for beam based additive manufacturing using free surface lattice Boltzmann methods. J Phys D: Appl Phys. 2014;47(27):275303.

[68] Solberg J, Hodge N, Ferencz R, et al. Diablo: A parallel, implicit multi-physics finite element code for engineering analysis user manual. LLNL-SM-674096, Lawrence Livermore National Laboratory; 2015.

[69] Strantza M, Ganeriwala RK, Clausen B, et al. Coupled experimental and computational study of residual stresses in additively manufactured ti-6al-4v components. Mater Lett. 2018; 231:221-224.

[70] Kapoor K, Yoo YSJ, Book TA, et al. Incorporating grain-level residual stresses and validating a crystal plasticity model of a two-phase ti-6al-4 v alloy produced via additive manufacturing. J Mech Phys Solids. 2018;121:447-462.

[71] Ali H, Ghadbeigi H, Mumtaz K. Residual stress development in selective laser-melted ti6al4v: a parametric thermal modelling approach. Int J Adv Manuf Technol. 2018;97(58):2621-2633. 